\title{
Forum: Genetic History
}

In den letzten Jahren hat sich eine internationale und mit der Gründung des Max-Planck-Instituts für Menschheitsgeschichte in Jena (MPI-SHH) auch eine starke nationale Debatte darum entwickelt, wie und ob ancient DNA (aDNA) verwendet werden kann, um damit Geschichte zu erforschen. NTM möchte diese inzwischen wissenschaftlich wie öffentlich laufende Kontroverse um die so genannte genetic history innerhalb der Rubrik „Forum“ aufgreifen und weiter erörtern.

Im vorliegenden Forum hat Gerrit Jasper Schenk Beiträge von Forschern des MPI-SHH sowie von Historikern und Archäologen zusammengetragen, die sich nicht nur, aber mehrheitlich mit Fragen von Migration und Bevölkerung zwischen Vorgeschichte und Mittelalter beschäftigen. Sie diskutieren wichtige Probleme und Herausforderungen wie den unterschiedlichen Gebrauch von Fachtermini, die Deckungsungleichheit von Genen und Kultur oder den engen Grat zwischen Kooperation und Konkurrenz der beteiligten Disziplinen mit je unterschiedlichen Erkenntniszielen und Fächerkulturen. Diese ersten Stellungnahmen möchte die NTM-Redaktion zum Anlass nehmen, um die Debatte um genetic history und aDNA in unseren Fächern weiterzuführen. Denn die historische, soziologische und kulturwissenschaftliche Wissenschafts- und Technikforschung hat zum einen in den letzten Jahren wichtige Arbeiten zur Geschichte von Populationsgenetik vorgelegt und unter anderem auch die historische Entstehung der Forschungsmethode aDNA kontextualisiert. Zum anderen begleitet Wissenschafts-, Technikund Medizingeschichte die Grundproblematik der Debatte schon länger, nämlich welche Rolle naturwissenschaftliche Methoden in der Geschichtswissenschaft einnehmen können und wo Grenzen und Unterschiede zwischen einem Untersuchungsobjekt als „epistemischem Ding“ (Rheinberger) und seiner Nutzung als historischer Quelle bestehen. Erinnert sei an ProxyDaten, wie sie über Eisbohrkerne, Pollen oder Baumringe in der Klima- und Umweltgeschichte ermittelt werden sowie an Replikationsmethoden in der „experimentellen“ Wissenschaftsgeschichte oder an die schon einige Zeit zurückreichenden Forschungen zu Yersinia pestis als Pesterreger innerhalb der Medizingeschichte.

Mit diesem ersten Forum möchte NTM daher zugleich zur Einsendung von Beiträgen zu dieser Debatte einladen, die in den folgenden Heften pu- 
bliziert werden sollen, um weiteren Perspektiven und Standpunkten ein Forum zu bieten. Wir erbitten daher die Zusendung von Beiträgen (in deutsch oder englisch, max. 15.000 Zeichen), die bis Ende Januar 2019 in der Redaktion eingehen sollten.

Die NTM-Redaktion 


\section{Geschichte als Naturwissenschaft? Zur Kontroverse um die aDNA-Forschung}

Gerrit Jasper Schenk

Seit der Gründung des Max-Planck-Instituts für Menschheitsgeschichte 2014 in Jena (MPI-SHH), ursprünglich als Institut für Geschichte und Naturwissenschaft konzipiert, erfährt die genetic history wachsende Aufmerksamkeit. Der bisher nur auf einer Webseite proklamierte Anspruch des Instituts ist hoch: Es gehe darum, dank einer mehrere Disziplinen integrierenden Wissenschaft „den traditionellen Graben zwischen Naturund Geisteswissenschaften“ zu überwinden und „grundlegende Fragen der menschlichen Evolution und Geschichte seit der Steinzeit zu erforschen“ (http://www.shh.mpg.de/68093/profile). In drei Abteilungen - Archäogenetik, Archäologie sowie Sprach-und Kulturevolution - sollen naturwissenschaftliche Methoden angewendet werden, um historische Erkenntnisse über die Koevolution von Genen und Kultur zu gewinnen, von Migration über die Entstehung früher Formen globaler Handelsbeziehungen bis zur Ausdifferenzierung von Sprachen, Kulturen und gesellschaftlichen Praktiken. Eine besondere Rolle spielen die Gensequenzierung sehr alter menschlicher Desoxyribonukleinsäure (aDNA) als Träger von Erbinformationen, evolutionsbiologische Theorien sowie quantitative naturwissenschaftliche Analysen materieller Zeugnisse der Vergangenheit.

Seit der spektakulären Analyse der Erbinformationen ägyptischer $\mathrm{Mu}$ mien durch Svante Pääbo (1985) herrschte in der internationalen Forscherszene eine Art Goldgräberstimmung. Zeitungsberichte informierten eine größere Öffentlichkeit über Erkenntnisse der neu entstehenden Disziplin „Molekulararchäologie“ über die Entdeckung von Neandertalergenen im Genom moderner Menschen bis zur Untersuchung des jungsteinzeitlichen Ötzi, der Mumie von Similaun. Der bei Pääbo promovierte Johannes Krause wurde einer der Gründungsdirektoren des neuen MPI in Jena. Die neue Forschungsrichtung wurde mit ihrer wachsenden Bedeutung und nachfolgend auch Institutionalisierung von Anthropologen (Marks 2013), Archäologen (Samida \& Eggert 2013) und Historikern (Samida \& Feuchter 2016; Schenk 2016) wahrgenommen und bald zunehmend kontrovers diskutiert, was sie mit ihrer Ausrichtung zur im weitesten Sinne historischen Forschung beitragen könne. Angesichts gegenwärtiger Tendenzen, race als genetisches Faktum zu naturalisieren, politisieren und instrumentalisieren, insistiert 
der US-Kulturanthropologe Jonathan Marks vehement, dass Menschen biokulturelle Wesen seien und man sich deswegen nicht auf eine Analyse ihrer genetischen oder soziokulturellen Dimension allein oder einer Korrelation getrennt erzielter Erkenntnisse beschränken könne, weil die Forschung alle ,genetischen Fakten' soziokulturell konstruiere. Auch die Archäologen und Historiker führen diese Konstruktion ,genetischer Fakten' kritisch an und bringen abgeleiteten und weitreichenden kulturhistorischen Aussagen etwa über migrierende Kulturträger Skepsis entgegen, doch halten Stefanie Samida, Manfred Eggert, Jörg Feuchter und Gerrit Jasper Schenk der neuen Forschungsrichtung beispielsweise zugute, substantielle Antworten zu konkreten Fragen wie der Verwandtschaft von Individuen eines Gräberfelds liefern zu können. Der Anspruch des neuen Jenaer Instituts, die beiden Wissenschaftskulturen zur Erforschung der Menschheitsgeschichte zu vereinen, macht dieses Experiment hochinteressant - nicht zuletzt auch für die Technik- und Wissenschaftsgeschichte. Doch springt ins Auge, dass die Publikationspraxis der naturwissenschaftlichen Akteure der genetic history das Gespräch über Fachgrenzen hinweg erschwert oder sogar verhindert, denn als Publikationsorgane dienen nahezu ausschließlich naturwissenschaftliche Zeitschriften - so verständlich diese Praxis in Zeiten der Prämierung von impact factor und h-Index auch sein mag.

Disziplinär verbindend wirken ein gemeinsames thematisches Interesse und gemeinsame Studienobjekte, die jedoch aus unterschiedlichen Perspektiven und mit zum Teil sehr divergenten Fragestellungen betrachtet werden: die biokulturelle Dimension menschlicher Existenz und als Quellen - in der Terminologie Droysens - ,Überreste', die aus der Vergangenheit dieser biokulturellen Existenz überliefert wurden oder erhalten blieben. Gerade historische Disziplinen, die sich mit Epochen beschäftigen, aus denen keine oder nur wenig Texte erhalten blieben (Ur- und Frühgeschichte, Archäologie, Spätantike- und Frühmittelalterforschung), oder die Themen bearbeiten, die in besonderem Maße auf materielle und biologische Strukturen der Vergangenheit eingehen (Umweltgeschichte), haben ein thematisches Interesse an der Zusammenarbeit. Besonders deutlich wird dies an der Forschung zur Epoche des Übergangs von der Spätantike zum Frühmittelalter in Europa, in der Phänomene wie die sogenannte Völkerwanderung eine Rolle spielen, wie etwa ein von Patrick Geary (2013) geleitetes - und seiner Einschätzung nach „revolutionäres“ - Forschungsprojekt zu den Langobarden zeigt. Folgerichtig hat sich die Wiener Schule der Frühmittelalterforschung um Walter Pohl (2016) eingehender mit der Herausforderung der genetic history für Archäologie und Geschichtswissenschaft auseinandergesetzt und vielleicht kann diese in Zukunft auch die Erforschung transkultureller Phänomene befruchten ${ }^{1}$. Es ist daher kein Zufall, dass Wolfgang Haak und Stephan Schiffels in ihrem Forumsbeitrag die genetische Herkunft der 
Europäer und genetische Spuren der frühangelsächsischen Migration in England als Fallbeispiele diskutieren. Ebenso wenig ist es Zufall, dass diese historisch, ideologisch und gegenwärtig auch politisch heiß diskutierte Thematik - Migration, Kulturkontakt und -konflikt - ausgerechnet jetzt eine Konjunktur im (nicht nur wissenschaftlich geführten) Diskurs erlebt. Man muss nicht Foucaults Regeln des Diskurses bemühen, um zu sehen, was jeder Historikerin und jedem Historiker aus der Geschichte der Disziplin vertraut ist: Gegenwartsinteressen bestimmen Fragestellungen und Erkenntnisinteressen notwendigerweise mit.

Disziplinär trennend wirken hingegen divergierende erkenntnistheoretische Prämissen und Erkenntnisziele, wissenschaftliche Methoden, Modelle und Praktiken, nicht zuletzt aber auch unterschiedliche Interessen und Konkurrenz um Ressourcen (öffentliche Aufmerksamkeit, Steuergelder, Renommee) und die oben erwähnte Publikationspraxis. Meines Erachtens resultiert die sich daraus ergebende und in diesem Forum dokumentierte Kontroverse in ihrem wissenschaftlichen Kern aus einer konträren Einschätzung des epistemischen Charakters der neuen Quelle „Genom“ und dem jeweils daraus Folgenden. Als Folge des linguistic turn haben die Geistes- und Sozialwissenschaften in den letzten Jahrzehnten verstärkt nach dem Charakter ihrer Untersuchungsobjekte, und allgemeiner Geschichte, als Konstrukt und Erzählung gefragt. Im Mittelpunkt stand die qualitative Analyse von Sinngebungsprozessen. Experimentiert wurde beispielsweise mit Methoden und Modellen der Ethnologie für räumlich ferne Kulturen, von der „teilnehmenden Beobachtung“ (Bronislaw Malinowski) der Feldforscher über die „dichte Beschreibung“ (Clifford Geertz) der interpretativen Ethnologie bis zu den interaktionstheoretischen Ansätzen der Manchester School der Sozialanthropologie. Gerade die in der genetic history aus neualtem Blickwinkel beleuchteten, aber eben nicht kritisch reflektierten Identitätspolitiken, die mit Ethnizität, Religion, Tradition, Sprache, Geschichte und Nation verbunden sein können, fanden das Interesse von Kulturanthropologen wie Historikern mit dem Ergebnis, dass Identitäten und Alteritäten höchst komplexe kulturelle Konstrukte sind (Hobsbawm 1983; Gone, Miller \& Rappaport 1999; Evans \& Marchal 2015).

Seit Ludwik Flecks (1980) schon 1935 angestellten Überlegungen zum naturwissenschaftlichen Denkstil war zudem nicht nur in der Wissenschaftsgeschichte und den Science and Technology Studies (STS) die Skepsis gegenüber dem epistemischen Status von hard facts der Naturwissenschaften als höherwertig gewachsen. Spätestens mit jüngeren Studien über die Zurichtung wissenschaftlicher Objekte in den Laboren der Naturwissenschaftler (Latour 2006) wurde es zur opinio communis, dass die hard facts der Naturwissenschaften in ihrem jeweiligen Kontext eine ganz bestimmte, aber eben keine höhere Valenz als kulturwissenschaftlich gewonnene Fak- 
ten haben. Auch wenn in jüngster Zeit das Interesse der Historikerinnen und Historiker an Objekten wiederkehrt und beispielsweise in der Umweltgeschichte und historischen Klimatologie naturwissenschaftliche Modelle und quantitative Methoden eine Rolle spielen, kann und will kaum ein Geistes- und Sozialwissenschaftler hinter diese Erkenntnis zurückgehen. Daher verwundert es, dass die jüngeren Arbeiten der STS zur humanen Populationsgenetik und evolutionären Anthropologie von den Allgemeinhistorikern, Archäologen und den naturwissenschaftlichen Vertretern der genetic history noch kaum zur Kenntnis genommen werden - selbst in diesem Forum (zur Geschichte des Forschungsfelds: Sommer 2015). Dabei haben viele Studien sehr klar auf die Koproduktion von sozialer und natürlicher Ordnung etwa am Beispiel der vornehmlich US-amerikanischen Erforschung von races (Reardon 2005; Bangham \& Chadarevian 2014; Spencer 2015) sowie der deutschen „Biologie der Juden“ (Lipphardt 2008) und der Blutgruppenforschung (Spörri 2013) hingewiesen.

Vor diesem Hintergrund ist es erfreulich, dass die Kontroverse um die molekulargenetischen Analysen alter DNA in jüngster Zeit verstärkt technik- und wissenschaftshistorisches Interesse findet. So hat Elsbeth Bösl überzeugend die „Entwicklung des Feldes“ seit den 1980er Jahren rekonstruiert und die „historische Gewordenheit des epistemischen Objekts alte DNA“ nachgewiesen (Bösl 2017: 13). Die kollektive Wissensproduktion versteht Bösl als „Coproduktion von Wissen und Wissenschaftsinstitutionen im Sinne Sheila Jasanoffs Konzept der Co-Production of Knowledge and Society“ (Bösl 2017: 49). Sie geht dabei über eine klassische Wissenschaftsgeschichte und Netzwerkforschung hinaus, indem sie die Emergenz des Forschungsfeldes wissenschaftssoziologisch als „Hype Cycle" analysiert, an dessen Ende vorerst die nüchterne Einsicht in die Notwendigkeit eines interdisziplinären Gesprächs über Möglichkeiten und Grenzen des neuen Forschungsfeldes stehe (Bösl 2017: 53, 319-338, $350 \mathrm{f}$.).

Die Erkenntnis, dass ein Gespräch über „Geschichte als Naturwissenschaft" dringend notwendig ist, bildet den Ausgangpunkt für das Forum. Es geht auf eine Podiumsdiskussion an der Technischen Universität Darmstadt am 26. Januar 2016 zurück (Redaktion 2016; Schenk 2016). Wolfgang Haak und Stephan Schiffels erörtern als Protagonisten des Jenaer MPI die Möglichkeiten der genetic history, gehen neben Methoden und Erkenntniszielen auch auf Probleme (Begrifflichkeit, Erkenntnisgrenzen) ein und stellen zwei Fallbeispiele vor. Als Kommentatoren nehmen mit Mischa Meier und Steffen Patzold zwei auf die Transformationsphase zwischen Spätantike und Frühmittelalter spezialisierte Historiker Stellung. Sie betonen, dass molekulargenetische Untersuchungen zwar nützliche Daten im Sinne einer neuen historischen Hilfswissenschaft liefern könnten, be- 
harren aber darauf, dass die Interpretation der Daten und die Bildung von Thesen Aufgabe der Geschichtswissenschaft bleiben müsse. Jan Keupp thematisiert die epistemologischen Grundlagen und Grenzen der genetic history und betont - gegen das naturwissenschaftliche Vertrauen in Makromodelle - aus allgemeinhistorischer und mediävistischer Perspektive die Erkenntnisinteressen der Historiker am jeweils konkreten Einzelfall. Anders der Mediävist Jörg Feuchter, der die ganz eigenständige Wissensproduktion der Genetiker hervorhebt, darin eine von der Geschichtswissenschaft ernstzunehmende Herausforderung sieht und zugleich für ein kritisches Gespräch der Disziplinen zum allseitigen Nutzen wirbt. Der abschließende Kommentar von Philipp von Rummel thematisiert aus der Perspektive des Archäologen den epistemischen Status aller Quellen, aus denen Kenntnis der Vergangenheit gewonnen werden kann. Er plädiert vor dem Hintergrund der bereits geleisteten archäologischen und historischen Forschung (und der Erfahrung ideologischer Verzerrungen) für eine kritische Integration der genetischen Quellen in die höchst komplexe Interpretation dessen, was vergangene Identitäten und Alteritäten kulturell ausmacht.

Die Diskussionsbeiträge zeigen meines Erachtens, dass der Austausch von Argumenten zwischen den unterschiedlichen Disziplinen zum Schaden aller Beteiligten noch deutlich zu wünschen übriglässt, während Tabubrecher wie David Reich das Thema „race“ in der Öffentlichkeit gefährlich vereinfachend besetzen (Reich 2018). Die historisch nachweisbare Vielschichtigkeit ethnischer Zuschreibungen und die Erkenntnis, dass diese oft mit historischen Machtverhältnissen verbunden waren und sind, bedarf dringend der kritischen Berücksichtigung in der alltäglichen Forschung. Der erkenntnistheoretische Anspruch der genetic history wirkt vor diesem Hintergrund zu hoch gegriffen. Im Sinne des eigenen Wissenschaftsanspruchs wird sie sich auch Falsifikationsmöglichkeiten von Seiten der Geisteswissenschaften öffnen und im gemeinsamen Gespräch ganz konkrete Fragen entwickeln müssen, die in der interdisziplinären Zusammenarbeit beantwortet werden können, so anstrengend das auch sein mag. Offensichtlich liegen auch in der genetic history vor dem Gipfelsturm die Mühen der Ebene.

\section{Anmerkungen}

1 Noch ohne Kenntnisnahme der genetic history, Borgolte 2012; vgl. dazu auch den ForumsBeitrag von Philipp von Rummel. 


\section{Literatur}

Bangham, Jenny und Soraya de Chadarevian 2014. Human Heredity after 1945: Moving Population Centre Stage. Studies in History and Philosophy of Biological and Biomedical Sciences (47): 45-49.

Bösl, Elsbeth 2017. Doing Ancient DNA. Zur Wissenschaftsgeschichte der aDNA-Forschung. Bielefeld: transcript.

Borgolte, Michael 2012. Das Langobardenreich in Italien aus migrationsgeschichtlicher Perspektive. Eine Pilotstudie. In: Borgolte, Michael und Matthias M. Tischler (Hg.). Transkulturelle Verflechtung im mittelalterlicher Jahrtausend. Europa - Ostasien - Afrika. Darmstadt: Wissenschaftliche Buchgesellschaft, 80-119.

Evans, Robert John Weston und Guy P. Marchal (Hg.) 2015. The Uses of the Middle Ages in Modern European States. History, Nationhood and the Search for Origins. Basingstoke: Palgrave Macmillan.

Fleck, Ludwik 1980. Entstehung und Entwicklung einer wissenschaftlichen Tatsache. Einführung in die Lehre vom Denkstil und Denkkollektiv, hg. v. Schäfer, Lothar und Thomas Schnelle, Frankfurt a. M.: suhrkamp.

Geary, Patrick J. 2013. Using Genetic Data To Revolutionalize Understanding of Migration History. Institute for Advanced Study, Princeton. The Institute Letter: 1, 5. URL: https:// www.ias.edu/sites/default/files/documents/publications/G13-14629_IASNL_SP13c.pdf (10.02.2018).

Gone, Joseph P., Peggy J. Miller und Julian Rappaport 1999. Conceptual Self as Normatively Oriented: The Suitability of Past Personal Narrative for the Study of Cultural Identity. Culture E Psychology (5): 371-398.

Hobsbawm, Eric 1983. Introduction: Inventing Traditions. In: Ders. und Terence Ranger (Hg.). The Invention of Tradition, Cambridge: Cambridge University Press, 1-14.

Latour, Bruno 2006. Gebt mir ein Laboratorium und ich werde die Welt aus den Angeln heben. In: Belliger, Andrea und David J. Krieger (Hg.). ANThology. Ein einführendes Handbuch zur Akteur-Netzwerk-Theorie. Bielefeld: transcript, 103-134.

Lipphardt, Veronika 2008. Biologie der Juden. Jüdische Wissenschaftler über „Rasse“ und Vererbung 1900-1935. Göttingen: Vandenhoeck \& Ruprecht.

Marks, Jonathan 2013. The Nature/Culture of Genetic Facts. Annual Review of Anthropology (42): 247-267.

Pääbo, Svante 18. April 1985. Molecular Cloning of Ancient Egyptian Mummy DNA. Nature (314): 644-645.

Pohl, Walter 2016. Editor's Introduction: The Genetic Challenge to Medieval History and Archeology. Medieval worlds. Comparative E Interdisciplinary Studies (4): 2-4.

Reardon, Jenny 2005. Race to the Finish. Identity and Governance in an Age of Genomics. Princeton: Princeton University Press.

Redaktion 2016. „Geschichte als Naturwissenschaft?“ Aus dem Feuilleton auf's Blog und vom Blog zur Podiumsdiskussion der ,Genetic History‘. Mittelalter. Interdisziplinäre Forschung und Rezeptionsgeschichte. URL: https://mittelalter.hypotheses.org/7584 (08.06.2018).

Reich, David 2018. How Genetics Is Changing Our Understanding of ,Race. The New York Times online, March 23. URL: https://www.nytimes.com/2018/03/23/opinion/sunday/ genetics-race.html (28.06.2018).

Samida, Stefanie und Jörg Feuchter 2016. Why Archaeologists, Historians and Geneticists Should Work Together - and How. Medieval worlds. Comparative E interdisciplinary studies (4): 5-21.

Samida, Stefanie und Manfred K.H. Eggert 2013. Archäologie als Naturwissenschaft? Eine Streitschrift. 2. Aufl. o. O. [Berlin]: Vergangenheitsverlag.

Schenk, Gerrit Jasper 24. Mai 2016. Geschichte als Naturwissenschaft? Podiumsdiskussion zu Perspektiven biologischer Forschung in der Geschichtswissenschaft an der TU Darmstadt - eine Nachbetrachtung. Mittelalter. Interdisziplinäre Forschung und Rezeptionsgeschichte. URL: http://mittelalter.hypotheses.org/8282 (09.02.2018). 
Sommer, Marianne 2015. Evolutionäre Anthropologie zur Einführung. Hamburg: Junius.

Spencer, Quayshawn 2015. Philosophy of Race Meets Population Genetics. Studies in History and Philosophy of Biological and Biomedical Sciences (52): 46-55.

Spörri, Myriam 2013. Reines und gemischtes Blut. Zur Kulturgeschichte der Blutgruppenforschung, 1900-1933. Bielefeld: transcript.

Gerrit Jasper Schenk

Institut für Geschichte

Technische Universität Darmstadt

Dolivostr. 15

64293 Darmstadt

Deutschland

schenk@pg.tu-darmstadt.de 


\section{Möglichkeiten und Grenzen molekulargenetischer Untersuchungen in den Geschichtswissenschaften}

Wolfgang Haak und Stephan Schiffels

\section{Was ist möglich im Zeitalter der Genomforschung?}

Die Entwicklung hochmoderner DNA-Sequenziertechnologien (Second, Third oder kurzum Next Generation Sequencing; NGS) hat die genetische Forschung im vergangenen Jahrzehnt revolutioniert. Innerhalb nur weniger Jahre war es möglich geworden, die Menge und Auflösungsstärke genetischer Daten millionenfach zu vergrößern (Metzker 2010). Wir verfügen heute über Technologien, die die Sequenzierung des gesamten menschlichen Genoms (drei Milliarden Basenpaaren) für wenige hundert Euro möglich machen. Anreiz und Ziel dieser genetischen Datengenerierung im neuen "Genom-Sequenzier-Zeitalter" sind klar definiert. Mit Hilfe hochauflösender Daten von möglichst vielen repräsentativen Gruppen (big data; siehe auch Kristiansen 2014) wollen wir detaillierte Antworten auf die großen Fragen der Menschheitsgeschichte finden: Woher kommt der Mensch? Wie und wann hat er sich in alle Ecken dieser Welt verbreitet? Welche Verwandtschaftsverhältnisse bestehen zwischen menschlichen Populationen und wie stellen diese sich im geschichtlichen Zusammenhang dar? Was macht uns einzigartig? Gibt es besondere Anpassungsleistungen unserer Spezies? Welche Rolle spielt die Umwelt in dieser Entwicklung? In welchem Wechselspiel stehen unsere Gene mit Krankheitserregern und deren Verbreitung? Und welche Rolle spielen unsere Gene im Spiegel kulturgeschichtlicher Errungenschaften?

Der Fokus liegt zunächst ganz klar auf einem besseren Verständnis der großen Zusammenhänge, dem big picture. Diese Herangehensweise ist dringend notwendig bevor man kleinregionale und feinchronologische Beziehungen untersuchen kann. Wesentliche Erkenntnisse aus der Genetik, vor allem auch seit den 1980er Jahren durch die Sequenzierung der mitochondrialen DNA (Cann et al. 1987), sind hinreichend bekannt: Zum Beispiel, dass die genetische Vielfalt in Afrika höher ist als bei Bevölkerungsgruppen außerhalb Afrikas und sogar mit Zunahme der Distanz zu Afrika weiter abnimmt. Dieser Befund gilt als Beweis dafür, dass die Wiege des modernen Menschen in Afrika stand (The 1000 Genomes Project Consor- 
tium 2015; Skoglund \& Mathieson 2018). Aus dieser Perspektive sind demnach alle Menschen dieser Erde Afrikaner.

Wirklich neu sind im Genom-Sequenzier-Zeitalter zwei wesentliche Punkte:

a) Im Gegensatz zur Sequenzierung der mitochondrialen DNA wird mit der Sequenzierung gesamter menschlicher Genome eine ungleich höhere Auflösung erzielt. Diese lässt uns neben den großen Zusammenhängen auch kleinräumigere Fragen aus der jüngeren Menschheitsgeschichte untersuchen.

b) Die Archäo- oder Paläogenetik, das heißt die Analyse alter DNA aus menschlichen Skelettresten, hat maximal von den technologischen Errungenschaften der NGS-Ära profitiert und konnte damit zur modernen Populationsgenetik aufschließen. Durch die Hereinnahme der Dimension Zeit ist es nun möglich ein zeitlich wie räumlich differenziertes, also dreidimensionales, Bild menschlicher Verwandtschaftsbeziehungen zu rekonstruieren (Lazaridis et al. 2014; Haak et al. 2015; Allentoft et al. 2015). In den vergangenen drei Jahren wurden ca. 1.000 alte menschliche Genome generiert, und die bislang erzielten Ergebnisse haben bereits für enorme Resonanz und mitunter deutliche Kritik auf/von Seiten der historischen Geisteswissenschaften, das heißt der Archäologie und der Geschichtswissenschaften, gesorgt. Warum dem so ist, soll hier erörtert werden und bildet den Gegenstand des gemeinsamen, fachübergreifenden Diskurses dieses Forums.

\section{Spürbare Dissonanzen}

Die Gründe für die durch die genetischen Ergebnisse hervorgerufenen spürbaren Dissonanzen sind vielerlei, lassen sich jedoch relativ einfach umreißen. Zum einen gibt es Missverständnisse zwischen den Disziplinen, die auf unterschiedliche Forschungstraditionen bzw. die Tatsache zurückzuführen sind, dass es keine gemeinsame wissenschaftliche Sprache oder Konventionen gibt. Dies wird zum Beispiel in unterschiedlichen Begriffsdefinition ersichtlich, die - wie im Folgenden am Begriff „Migration“ verdeutlicht wird - sehr unterschiedliche Assoziationen hervorrufen können. Dass dies selbst innerhalb der Geisteswissenschaften ein Problem semantischer Natur darstellt, zeigt die Feststellung, dass beispielsweise Migration in der Soziologie nur eine von vielen möglichen Formen menschlicher Mobilität darstellt, in der Archäologie jedoch der Mobilität ebenbürtig, ja gar gegenüber gestellt wird. Dieser Umstand wird erwartungsgemäß komplexer, insofern auch die Biologie (und hier die Populationsbiologie) diesen Begriff nutzt, 
den sie nicht nur großzügig auch auf Faunenkomplexe anwendet, sondern zudem auch wenig zwischen kurzzeitigen und reversiblen Ereignissen (wie etwa der saisonalen Wanderung von Zugvögeln oder Rentieren; bird/reindeer migration) und langfristigen, aber einmaligen Phänomenen im Sinne von Expansionen unterscheidet (beispielsweise der graduellen Besiedlung von Inselgruppen oder Kontinenten).

Ein weiterer Stein des Anstoßes ist die gemeinsame Interpretation von archäologischen, linguistischen und genetischen Befunden sowie die anschließende Verknüpfung zu einem kollektiven Narrativ. Dies geschieht vor dem historischen Hintergrund der vereinfachenden Gleichung pots = people = language, ein hinlänglich bekanntes Konzept der Archäologie, welches zu Zeiten des Zweiten Weltkriegs ideologisch missbraucht wurde (Grünert 2002) und daher - wie man hoffte - bereits verworfen war. Dieser fatale Missbrauch archäologischer Thesen hatte negative Folgen für die deutsche, aber auch internationale Archäologie und hat damit das Forschungsfeld nachhaltig geprägt. Manche Kritiker sehen daher in den genetischen Resultaten, welche Implikationen für Herkunft und Migration haben, ein erneutes Heraufbeschwören der alten, tot geglaubten, Geister in frischem Gewand.

\section{Zum ideologischen Ballast}

Die direkte Verknüpfung von archäologischer Sachkultur als Spiegelbild der Kultur eines klar definierten Volkes mit (naturgemäß) gemeinsamer Sprache bildete auch die ideelle Grundlage der „Methode der Siedlungsarchäologie“, welche von Gustav Kossinna im 20. Jahrhundert vorgeschlagen wurde (Kossinna 1911; Eggers 1959). Dieser hatte dem archäologischen Verbreitungshorizont der endneolithischen „Kultur mit Schnurkeramik“ nicht nur ein Volk zugewiesen und diese Kultur damit reifiziert, das heißt ihr damit ein Gesicht gegeben, sondern diesem Volk auch den Ursprung des Proto-Indoeuropäischen zugesprochen. Selbiges Konzept wurde auch auf die Germanen übertragen, womit der ideologische Missbrauch in Verbindung mit moralistischen Fehlschlüssen im Dritten Reich naheliegt. Dieser ideologische Missbrauch hatte zur Folge, dass in den Nachkriegsjahren nicht nur die Verwendung des Konzepts, sondern jede mögliche Verbindung von Archäologie, Sprache und Sprach- bzw. Sachkulturträgern, das heißt einer Bevölkerungsgruppe, ausgeschlossen wurde. Ebenso wandte man sich von Konzepten der Verbreitung von Sachkultur ab, welche Migration bzw. Expansion von Völkern als Erklärung beinhaltete, um nicht erneut Gefahr zu laufen politisiert zu werden. Bald wurde gar ein gegensätzlicher Trend im Wissenschaftsklima deutlich, der eine neutrale Auseinanderset- 
zung mit dem Thema Migration beinahe unmöglich machte. David Anthony konnte mit seinem Beitrag "The Baby and the Bathwater" die Entwicklung zwar wieder in gemäßigtere Fahrwasser zurückführen (Anthony 1990), die Skepsis und stete Alarmbereitschaft blieb jedoch. Auch wenn einige Autoren Migration als Erklärungsansatz inzwischen wieder aufgreifen (Burmeister 2000), wird das Thema in der Archäologie gerne vermieden.

\section{Was kann die genetische Forschung wirklich leisten?}

Die Dreidimensionalität der ancient-DNA (aDNA)-Forschung ermöglicht heute den direkten Nachweis von Migrations- und Vermischungsereignissen (Haak et al. 2015; Skoglund et al. 2016; Schiffels et al. 2016; Fu et al. 2016; Lipson et al. 2017; Olalde et al. 2018; Posth et al. 2018). Dies erfolgt über den Vergleich von biologischen Merkmalskomponenten in Raum und Zeit. Damit lassen sich die Ergebnisse in einer diachronen Gesamtschau zu einer Beweiskette zusammenführen (Abb. 1).

Ein wesentlicher Vorteil von aDNA-Ergebnissen prähistorischer Individuen ist, dass diese sehr gut kontextualisiert werden können (siehe jedoch Vorbehalt/caveat unten). In der Regel gibt es für jedes Individuum eine genaue Ortsangabe (geografische Koordinaten). Zudem können sie durch Grabbeigaben direkt mit materieller Sachkultur assoziiert und darüber hinaus nicht nur relativ, sondern per Radiokarbondatierung auch absolut datiert werden. Im Vergleich des genetischen Profils mit anderen Individuen in Raum und Zeit lassen sich dann Verwandtschaften feststellen. Im Falle großer genetischer Ähnlichkeiten mehrerer Individuen muss aus biologischer Sicht von einer Population bzw. konkret von einem Heiratskreis gesprochen werden. Umgekehrt deuten Unterschiede auf Migrations- und Mischungsereignisse hin, deren Richtung und Größenordnung festgestellt und zeitlich eingeordnet werden kann (Abb. 1).

Detaillierte Studien moderner Population haben gezeigt, dass sich mehr als 80 Prozent der bekannten genetischen Variabilität unterschiedlicher Menschen in Großgruppen, wie etwa Europäern oder Asiaten, finden (The 1000 Genomes Project Consortium 2015). Diese hier betrachteten Unterschiede sind einzelne Basenunterschiede im Genom (Single Nucleotide Polymorphisms; SNPs) und treten mit einer bestimmten Häufigkeit, der Allelfrequenz auf ${ }^{1}$, die sich wiederum zwischen den einzelnen Populationen unterscheidet. Genetische Unterschiede zwischen menschlichen Populationen sind grundsätzlich sehr klein, so beträgt etwa die genetische Variabilität zwischen Spaniern und Deutschen weniger als ein halbes Prozent der genetischen Variabilität innerhalb dieser Gruppen, so dass sich der Großteil der 


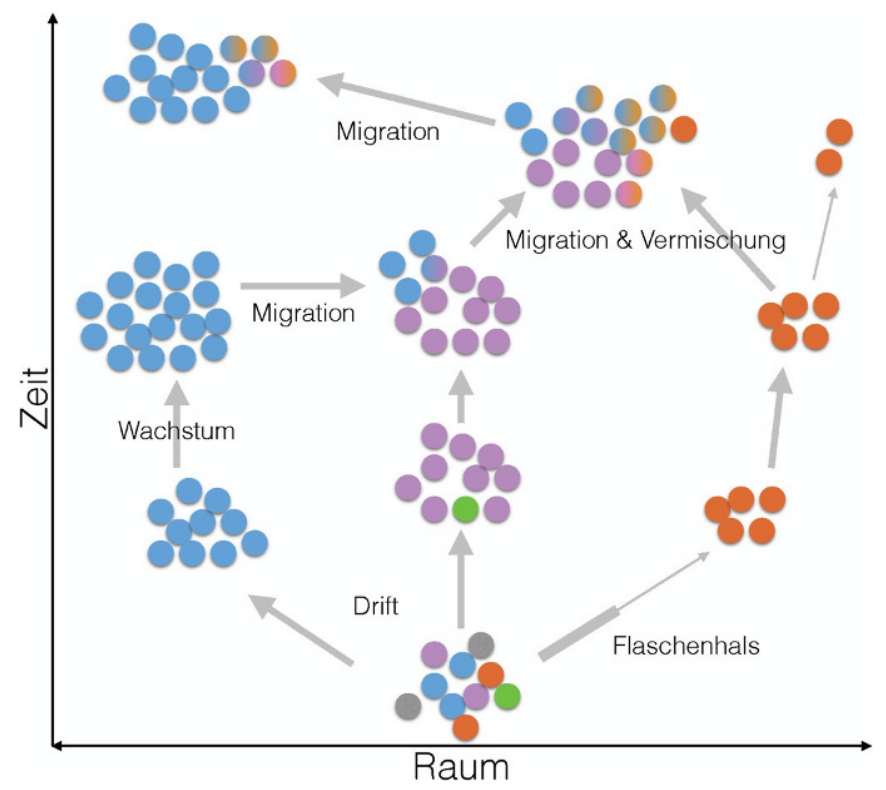

Abb. 1 Darstellung populationsgenetische Prozesse in Raum und Zeit. Schematisch skizziert sind Prozesse genetische Differenzierung durch Drift, geografische Isolation und genetischen Flaschenhals, sowie serielle Prozesse wie Migration und Vermischung, die sich in der diachronen Gesamtschau gut erkennen lassen (Entwurf und Umsetzung: Wolfgang Haak).

genetischen Vielfalt des Menschen nicht zwischen unterschiedlichen Populationen niederschlägt, sondern innerhalb einzelner Populationen. Dies bedeutet umgekehrt, dass sich die Mehrheit der genetischen Vielfalt der Europäer bereits erfassen lässt, indem man nicht weit voneinander entfernte Individuen, beispielsweise aus Rheinhessen und dem Schwarzwald, untersucht. Die Individuen beider Regionalgruppen haben eine ähnliche Allelfrequenz, die sich aber wiederum von Andalusiern in Spanien oder Esten in Baltikum unterscheidet, wenngleich Letztere die absolute Anzahl der häufigen genetischen Varianten teilen.

Auch ohne diachrone Datenerhebung ist es möglich die genetische Geschichte von Populationen nachzuzeichnen. Dies beruht auf der Erkenntnis, dass genetischen Veränderungen (Basensubstitutionen bzw. Mutationen) eine zeitliche Konstante innewohnt, welche bereits in den 1960er Jahren als „molekulare Uhr" beschrieben wurde (Zuckerkandl \& Pauling 1965). Diese Konstante beschreibt die Beobachtung, dass die Substitutionsrate im Erbgut über lange Zeiträume gleich hoch bleibt, sich jedoch von Spezies zu Spezies unterscheidet, nicht zuletzt weil die zeitliche Länge einer Generation deutlich abweicht (25-30 Jahre beim Menschen, 20 Jahre bei Schimpansen, zwei Jahre bei Mäusen, vgl. dazu Pacifici et al. 2013). 
Jedes Individuum trägt durchschnittlich 80 Mutationen in sich, die neu entstanden sind und nicht von den Eltern vererbt wurden (Narasimhan et al. 2017). Etablieren sich diese anfänglich privaten Mutationen und sind anschließend in mehr als einem Prozent aller Individuen einer Population bzw. mehrerer Populationen zu finden, zählen solche SNPs zu den häufigen Varianten (common variants). Die Frequenzen häufiger Varianten in menschlichen Populationen verändern sich über den Lauf der Zeit stetig und zufällig, und diese neutralen Veränderungen machen einen Großteil der genetischen Unterschiede zwischen menschlichen Populationen aus. Je länger Populationen voneinander getrennt sind und kein Genaustausch stattfindet, desto mehr Frequenzunterschiede häufen sich in den jeweiligen Populationen an, ein Prozess, der als „Gendrift" bezeichnet wird (Jobling et al. 2013) (Abb. 1). Umgekehrt bedeutet dies, dass Populationen, die sich geografisch nahe sind, erst kurze Zeit voneinander getrennt sind (beispielweise bei der schrittweisen Kolonisierung von Inselketten) oder regelmäßig Kontakt haben, ähnliche Frequenzprofile ausweisen (Novembre 2008; Ralph \& Coop 2013). Mit diesen Frequenzprofilen ist genetische Forschung in der Lage Populationen zu charakterisieren und gleichermaßen Rückschlüsse über die genetische $\mathrm{Zu}$ sammensetzung bzw. die geografische Herkunft zu ziehen.

Im Gegensatz zu häufigen Varianten stehen bei höherem Sequenzieraufwand auch seltene Varianten (rare variants) für populationsgenetische Analysen zur Verfügung, die nur in wenigen Individuen bzw. Populationen vorkommen (Abb. 2) und daher feinere Rückschlüsse auf Verwandtschaftsbeziehungen zulassen (The 1000 Genomes Project Consortium, 2015; Mathieson \& Reich 2017). Aus den Eigenschaften dieser genetischen Varianten ergeben sich naturgemäß verschiedene zeitliche wie auch räumliche Auflösungen, die in der Populationsgenetik - je nach Fragestellung - angewendet werden können. Häufige Varianten eignen sich für großräumige und zeitliche tiefere Fragestellungen (the big picture, etwa die Besiedlungsgeschichte von Kontinenten), wohingegen sich die seltenen Varianten für jüngere Zeiträume und auch regionale Fragestellungen eignen (Schiffels et al. 2016).

Diese beiden genetischen Blickwinkel schließen sich keinesfalls gegenseitig aus und auch der Übergang von häufigen zu seltenen Varianten ist keinesfalls strikt und abrupt. Im Gegenteil: In vielen Studien werden Daten beider Kategorien erhoben und dann während der Analyse von grober zu feiner Auflösung fokussiert. Im Folgenden stellen wir zwei Fallstudien vor, die diese beiden Blickwinkel vertreten.

\section{Fallstudie 1: Die genetische Herkunft der Europäer}

Die Verwendung von Methoden zur Analyse von Allelfrequenzen häufiger genetischer Varianten hat in den letzten Jahren zu wesentlichen Durchbrüchen bei der Rekonstruktion der genetischen Menschheitsgeschichte geführt, 

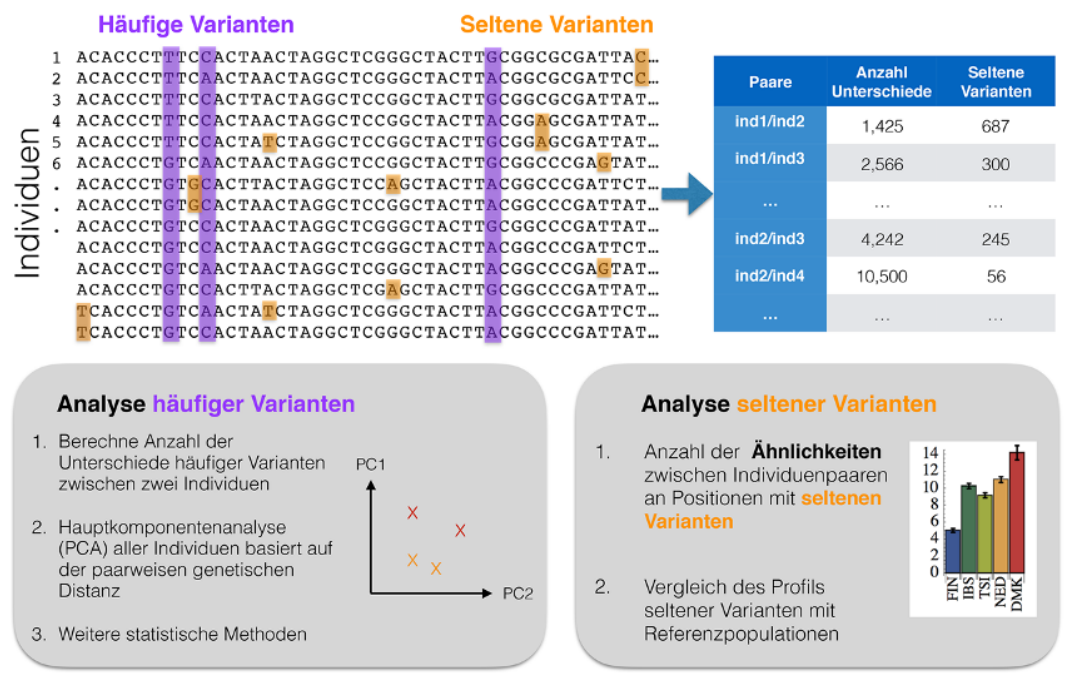

Abb. 2 Schematischer Darstellung der Analyse häufiger und seltener Varianten im menschlichen Genom (Entwurf und Umsetzung: Stephan Schiffels).

nicht zuletzt weil sich sowohl auf Seiten moderner als auch vergangener Populationen eine sehr große Anzahl von Individuen genetisch charakterisieren ließ (Lazaridis et al. 2014; Jeong et al. 2018). Insbesondere in Europa bietet ein weitgehend gemäßigtes Klima gute Voraussetzungen für DNAErhaltung. Die Ergebnisse mehrerer Forschungsarbeiten haben gezeigt, dass Westeurasien vor 8.000-10.000 Jahren genetisch noch ganz anders aussah, das heißt die genetische Variabilität sich deutlich von der heutigen unterschied (Lazaridis et al. 2014). So lassen sich vier genetische Eckpfeiler definieren, welche sich in vorbäuerlichen Gesellschaften noch unverkennbar voneinander unterscheiden: i) Jäger-Sammler-Gruppen in Westeuropa und sehr ähnlich, aber unterscheidbar, solche in Osteuropa, ii) die ältesten verfügbaren Individuen aus dem Anatolischen Neolithikum und iii) dem Natufien und dem Präkeramischen Neolithikum der Levante und iv) Jäger-Sammler-Gruppen in Georgien und dem Iran (Lazaridis et al. 2014; Lazaridis et al. 2016; Haak et al. 2015; Jones et al. 2015; Broushaki et al. 2016; Mathieson et al. 2015). Aus genomweiten Daten frühneolithischer Kontexte wird nun ersichtlich, dass im Zuge der Sesshaftwerdung sowie Ausbreitung von Ackerbau und Viehzucht vor ca. 6.000-8.000 Jahren Migrationen, Vermischungen und Verlagerungen stattgefunden hatten. So hat sich die genetische Komponente aus Anatolien mit der Ausbreitung des Ackerbaus über ganz Europa verbreitet und dort die ansässige genetische Signatur der westlichen und östlichen Jäger-Sammler-Gesellschaften überlagert und sich langsam ver- 
mischt (Lazaridis et al. 2014; Haak et al. 2015; Mathieson et al. 2015; Lazaridis et al. 2016). Parallel dazu hatte sich im Zuge der Entwicklungen von semi-nomadischen Vieh- und Weidewirtschaften in den eurasischen Steppen eine südkaukasisch/iranische genetische Komponente mit den ehemaligen Jäger-Sammler-Gruppen Osteuropas vermischt. Diese genetische ,Steppenmixtur' verbreitet sich dann mit der aufkommenden Bronzezeit - einer Zeit maßgeblicher gesellschaftlicher Umbrüche und Innovationen (etwa Hansen \& Müller 2011) - nach Sibirien und auch Westeuropa aus, wo sie sich massiv in bronzezeitlichen Gesellschaften niederschlug und die Herausbildung heutiger Populationen mitbestimmte (Mathieson et al. 2015; Haak et al. 2015; Allentoft et al. 2015). Die Archäogenetik konnte damit deutlich zeigen, dass Epochen wesentlicher kultureller Umbrüche in der Vorgeschichte auch von genetischen Umbrüchen durch Migrationen begleitet waren.

Diese neuen Erkenntnisse lassen auch frühere Ergebnisse aus genetischen Studien in Europa in neuem Licht erscheinen. So wurde etwa in einer genetischen Studie moderner Europäer 2008 eindrucksvoll gezeigt (Novembre et al. 2008), dass sich in den genetischen Unterschieden heutiger Europäer in gewissem Maße die Geographie Europas wiederspiegelt (und nicht etwa Sprach- oder Landesgrenzen). In einer ersten Interpretation dieser Ergebnisse ging man davon aus, dass es sich hier um eine klassische Folge von Gendrift im Zusammenhang mit isolation by distance handelt. Man konnte die Ergebnisse zunächst erklären, ohne größere Migrationen oder Umbrüche in der Vergangenheit anzunehmen. Erst durch die neuen Ergebnisse der Archäogenetik ließ sich zeigen, dass diese Schlussfolgerung vorschnell war: Der Zusammenhang zwischen Geographie und Genen der heutigen Europäer ist das Ergebnis von mehreren großen Vermischungen, die aus großen Umwälzungen in der Vergangenheit hervorgingen. Auch zeigen diese Entwicklungen, dass die genetische Untersuchung von heutigen Gruppen nur begrenzt Rückschlüsse auf deren Vorgeschichte zulassen, gerade weil die älteren Ereignisse von zeitlich jüngeren überlagert werden können und damit nicht mehr sichtbar sind. Die oft zitierte "genetische Zeitreise“, das heißt die Analyse genomweiter Daten prähistorischer Individuen, wird damit unabdingbar, möchte man das Kommen und Gehen menschlicher Populationen über tiefere Zeiträume verstehen (Pickrell \& Reich 2014).

Fallstudie 2: Genetische Spuren der frühangelsächsischen Migration in England

Wie oben gezeigt, stellen die prähistorischen Gesellschaften ab der europäischen Bronzezeit bereits eine Mischung mehrerer Komponenten dar und unterscheiden sich nur subtil in den jeweiligen Anteilen der auf Frequenzunterschieden häufiger genetischer Varianten basierten genetischen Eckpfeiler. Für jüngere Epochen ist daher eine feinkörnigere Auflösung er- 
forderlich, nicht zuletzt auch, weil beispielsweise eine Beschreibung von Herkunftsprofilen mittelalterlicher Individuen mit mesolithischen Komponenten einen $\mathrm{zu}$ großen zeitlichen und kontextuellen Hiatus ergeben würden.

Dieser Herausforderung haben sich die beiden Autoren mit einer Studie gestellt, in der sie die gesamten Genome späteisenzeitlicher und frühmittelalterlicher Individuen aus britischem und angelsächsischem Kontext analysiert haben (Schiffels et al. 2016; Schiffels \& Sayer 2017). Der Fokus auf seltene genetische Varianten, welche mit Hilfe von ausreichend großen Referenzpopulationen aus geografisch benachbarten, das heißt für die Fragestellungen relevanten Regionen, bestimmt wurden, erlaubte es zwischen den verschiedenen historischen Gruppen zu unterscheiden. So deutet beispielsweise ein Überschuss an privaten seltenen Mutationen in einer Population auf relative Isolation hin, wohingegen die Überlappung (sharing) seltener Mutationen zwischen zwei Populationen auf eine engere Beziehung bzw. Genfluss in relativ jüngerer Zeit hindeutet. Mit Hilfe seltener genetischer Varianten konnte in dieser Studie eindeutig gezeigt werden, dass sich die Herkunft früh- und mittelangelsächsischer Individuen klar von der Herkunft solcher aus der späten Eisenzeit unterscheidet. Konkret teilen Individuen aus früh- und mittelangelsächsischen Fundkontext deutlich mehr seltene Mutationen mit heutigen Holländern als die späteisenzeitlichen Individuen. Anhand dieser Unterschiede und der Analyse moderner britischer Genome konnte schließlich berechnet werden, dass im Mittel 38 Prozent der Vorfahren heutiger Engländer angelsächsische Migranten waren. Diese erste direkte Schätzung hat die bis dahin aus modernen Daten abgeleiteten Schätzungen von zehn bis 90 Prozent deutlich eingeschränkt (Leslie et al. 2015). Die als angelsächsisch angesprochenen Individuen des Fundplatzes Oakington (Cambridgeshire, UK) zeigten zudem sowohl lokale, ortsfremde sowie auch vermischte Signaturen, was vor dem einheitlichen archäologischen und damit kulturellen Hintergrund auf einen gewissen Grad der Assimilierung und Integration innerhalb dieser angelsächsischen Gruppe spricht. Diese Erkenntnis beruht ausdrücklich auf der gemeinsamen Analyse der genetischen und der archäologischen Daten und zeigt beispielhaft, wie die beiden Disziplinen verknüpft werden können, um nicht nur Migration direkt nachzuweisen, sondern auch festzustellen, wie diese konkret vor Ort zu Vermischungen geführt hat oder eventuell auch nicht.

Die genannte Studie macht vor dem Hintergrund der vielgestaltigen menschlichen Kulturausprägungen deutlich, dass aufgrund wie auch immer gearteter künstlicher Barrieren (wie etwa sprach- oder glaubensbedingter Heiratsgrenzen), aber auch geographischer Distanz (hier die Nordsee), feine biologische Unterschiede feststellbar sind, die mit Hilfe zeitlicher Tiefenschärfe durch ancient DNA jedoch an Aussagekraft gewinnen. Von Seiten 
der Archäogenetik bietet sich der vorgestellte Methodenkatalog ebenso für andere offene Fragen in der Historie bzw. Archäologie an, allen voran die sowohl offensichtlichen wie auch intensiv debattierten Fragen zur Völkerwanderungszeit, die ein ideales Forum bieten, um die vorhandene Methodik auszureizen (Amorim et al. 2018).

\section{Transdisziplinäre Kontextualisierung der genetischen Ergebnisse}

Die Erweiterung des Erkenntnisspielraums kann nur mit Hilfe des soziokulturellen Kontexts aus archäologischen und historischen Quellen erfolgen. Durch eine transdisziplinäre Sichtung der Gesamtdatenlage kann dann beurteilt werden, ob eine Beschreibung vermeintlicher genetischer bzw. kultureller Entitäten in verallgemeinerter Form Gültigkeit beizumessen ist, sofern diese ein plausibles hypothetisches Rahmenwerk liefert, das formal getestet werden kann. Eine Vereinfachung der Sachlage dient hier als Mittel zum Zweck und muss zur Beschreibung der Allgemeinbefunde zunächst in Kauf genommen werden. Konkrete Beispiele für Simplifizierungen dieser Art sind beispielsweise Begriffe wie „Jäger-Sammler“, „Frühbauern“, „Schnurkeramiker“, „Kelten“, „Etrusker“, „Langobarden“, „Angelsachsen“, die oberflächlich die Vergegenständlichung (Reifikation) von materieller Kultur, Sprache, oder gar einer Wirtschaftsweise widerspiegeln (Furholt 2017). Die Gefahr kausaler Rückschlüsse solcher Benennungen ist jedoch groß, denn natürlich muss beispielsweise nicht jedes Individuum, welches im kulturellen Kontext einer agrarischen Gesellschaft bestattet wurde, ein Ackerbauer oder Viehzüchter gewesen sein. Ein interessantes Beispiel liefert ein Individuum, das in einer frühneolithischen Grube der Körös-Kultur bestattet wurde, allerdings die genetische Signatur eines westlichen JägerSammlers trägt (Gamba et al. 2014). Die Benennung nach charakteristischer Keramik (z. B. Glockenbecher, Bandkeramiker etc.) kann ebenfalls nur eine temporäre Kategorisierung für vorgeschichtliche Gruppen sein. Allerdings wird eine einheitliche Kurzbeschreibung der zeitlichen, kulturellen und genetischen Eigenschaften (prä-)historischer Individuen von allen beteiligten Disziplinen gewünscht, nicht zuletzt um den Überblick über die rasch anwachsende Zahl genomweiter Daten zu wahren. Diesbezüglich ist eine Bestrebung des Max-Planck - Harvard Forschungszentrums für die archäologisch-naturwissenschaftliche Erforschung des antiken Mittelmeerraums (MHAAM) zu erwähnen, die Empfehlungen zur Benennung bzw. Nomenklatur (prä-)historischer Individuen sowie deren Gruppen vorschlägt (Eisenmann et al., in Vorbereitung). 
Grundlegend sei erwähnt, dass bei allen gut gemeinten Bestrebungen zwei Prozesse hinsichtlich der Datengenerierung zu trennen sind: Auf der einen Seite steht die Feststellung einer quantifizierbaren, biologischen Einheit, das heißt einer Gruppe mit gemeinsamem genetischen Profil, welche die Fortpflanzungsgemeinschaft widerspiegelt. Demgegenüber präsentiert sich die Kategorisierung und Kontextualisierung derselben anhand charakteristischer kultureller, geografischer oder zeitlicher Merkmale, von der nur wenige diskreter Natur und in erster Linie Konventionen sind. Diese sind flexibel und können daher vereinfachende oder ,vermenschlichte' Benennungen (Bandkeramiker) aushalten, die zwar nicht formal korrekt, aber in Kürze informativer und unmissverständlicher sind als rein sachliche Lösungen (wie etwa Population 1, 2, 3 etc.).

\section{Sind Genome weniger Individuen repräsentativ für eine Epoche?}

Eine weitere häufig geäußerte Kritik seitens der Geisteswissenschaften beschäftigt sich mit der Frage, inwieweit nur wenige Individuen einer Gruppe/ einer Epoche diese überhaupt repräsentieren können. Im Falle von einem oder nur wenigen Fundplätzen stellt sich zudem die Frage, ob dieser die Norm oder die Ausnahme darstellt. Erwägungen, die durchaus berechtigt sind, zumal genetische Analysen alter DNA in den ersten Jahren ausschließlich auf die maternal erbliche mitochondriale DNA (mtDNA) beschränkt waren, ${ }^{2}$ die eine statistisch zuverlässige Stichprobenanzahl benötigte.

Dagegen birgt die genomweite Analyse den enormen Vorteil, dass Abschnitte der Kern-DNA in jeder Generation neu kombiniert werden (Jobling et al. 2013). Durch den Prozess der Rekombination multipliziert sich die Information, die über alle vorausgehenden Generationen eines Individuums gewonnen werden kann, mit der Anzahl der Vorfahren im Quadrat. ${ }^{3}$ Der limitierende Faktor der tatsächlichen effektiven Populationsgröße ist jedoch schnell erreicht, da in kleinen Gruppen viele Vorfahren (teil-)identisch sind und sich damit rechnerisch aufheben (so genannter Ahnenschwund). Damit wächst die Anzahl an Vorfahren, je weiter man zurückblickt, sehr schnell an, und umfasst nach nur wenigen Generationen fast die komplette Population (Abb. 3). Vor diesem Hintergrund wurde berechnet, dass alle heutigen Europäer in den letzten 2000 Jahren mindestens einen gemeinsamen Vorfahren haben (Ralph \& Coop 2013). Durch die Rekombinationseigenschaft der Kerngenome liefern diese eine ungleich höhere genetische Auflösung im Vergleich zu uniparental vererbten Markersystemen (das heißt mtDNA und Y-Chromosom) und schon ein Genom eines prähistorischen Individuums kann einen zeitlichen Rückblick auf die Population 


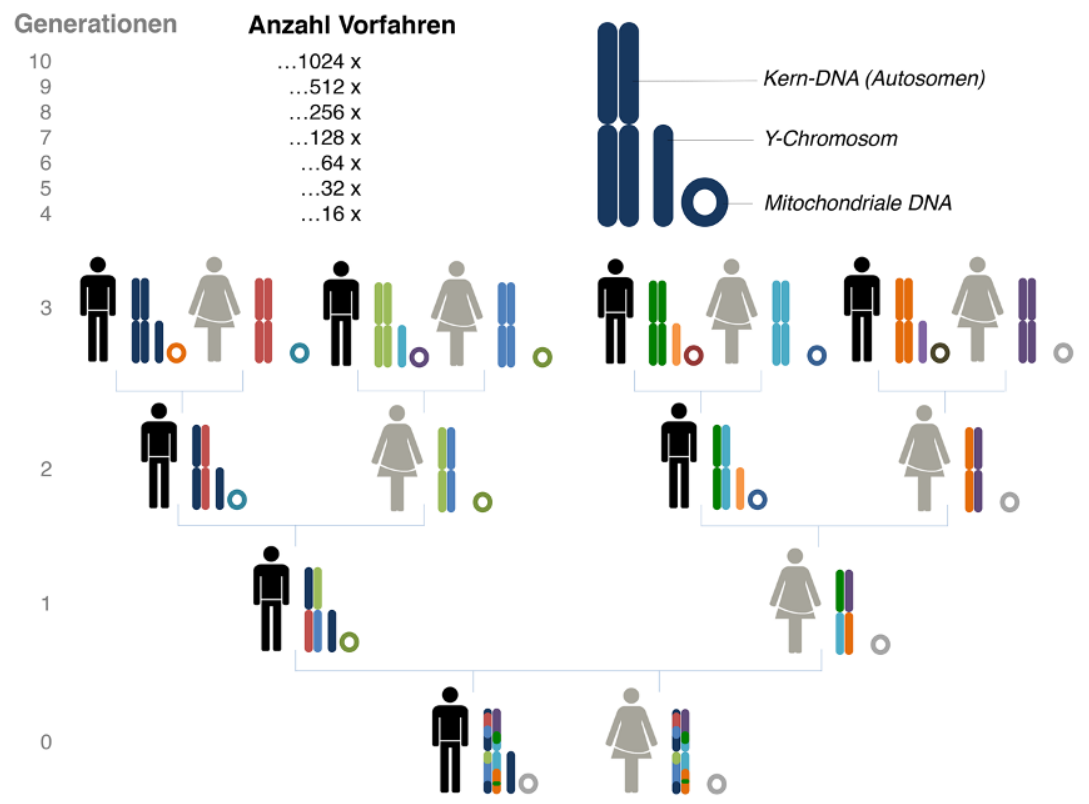

Abb. 3 Genealogischer Stammbaum. Mitochondriale DNA wird über die mütterliche Seite vererbt, das Y-Chromosom über die väterliche Seite. Die homologen Chromosomen der Kern-DNA (Autosomen) werden in jeder Generation zufällig rekombiniert, wobei jeder Elternteil jeweils eine Kopie beiträgt, welche selbst eine rekombinierte Form der vorausgehenden Generation darstellt. Eine Hochrechnung auf zehn Generationen stellt die theoretische Größe der Ahnengemeinschaft dar (Entwurf und Umsetzung: Wolfgang Haak).

und deren Struktur in der Vergangenheit liefern. Theoretisch reichen für die genetische Charakterisierung einer (prä-)historischen Population ein oder nur wenige repräsentative Individuen aus. Selbstverständlich rückt hierbei die sorgfältige, kontextbasierte Auswahl solcher Individuen in den Vordergrund, ein Umstand, der wiederum die Brücke zur Archäologie und den Geschichtswissenschaften schlägt.

\section{Fazit}

Die Analyse alter DNA aus menschlichen Skelettresten ist besonders reizvoll, weil sie die Möglichkeit bietet, die genetische Zusammensetzung heutiger und vergangener Populationen direkt miteinander zu vergleichen. Dadurch können auch Populationen aufgespürt werden, die heutzutage nicht mehr in derselben Form existieren oder keine Nachkommen hinterlassen haben. Der diachrone Vergleich deckt größere Verschiebungen in der gene- 
tischen Struktur menschlicher Populationen zwischen einzelnen Zeitperioden auf und liefert damit wertvolle Hinweise auf epochale Bevölkerungsumbrüche und Veränderungen in der Mobilität bzw. auf die Ausbreitung einzelner Gruppen in der Vorgeschichte. Mithilfe der Analysen von alter DNA können so Hypothesen aus der Archäologie und der Historie getestet werden

\section{Anmerkungen}

1 Das menschliche Erbgut ist diploid, das heißt jedes Chromosom (Autosom) liegt doppelt vor. Man spricht daher von zwei Allelen und ein Basenunterschied kann daher homozygot (beide Allele sind gleich) oder heterozygot (die Allele sind unterschiedlich) sein.

2 Die mitochondriale DNA wird ausschließlich von der Mutter an die Kinder vererbt und jeweils nur von den Töchtern weitergegeben.

3 Jedes Individuum trägt die genetische Information beider Eltern, aller vier Großeltern, aller acht Urgroßeltern, den 16 Ururgroßeltern usw. Berechnen wir zehn Generationen mit einer Dauer von 25 Jahren, so liefert uns ein Genom genetische Information zu mehr als 1024 Individuen, welche in den letzten 250 Jahren gelebt haben und ihren Beitrag zum untersuchten Individuum geliefert haben.

\section{Literatur}

Allentoft, Morton E. et al. 2015. Population Genomics of Bronze Age Eurasia. Nature (522): 167-172.

Amorim, Carlos Eduardo G. et al. 2018. Understanding 6th-Century Barbarian Social Organization and Migration through Paleogenomics. bioRxiv. URL: https://doi.org/10.1101/ 268250 (28.06.2018).

Anthony, David W. 1990. Migration in Archaeology: The Baby and the Bathwater. American Anthropologist (92): 895-914.

Broushaki, Farnaz et al. 2016. Early Neolithic Genomes from the Eastern Fertile Crescent. Science (353): 499-503.

Burmeister, Stefan 2000. Archaeology and Migration - Approaches to an Archaeological Proof of Migration. Current Anthropology (41): 539-567.

Cann, Rebecca L., Mark Stoneking und Allan C. Wilson 1987. Mitochondrial DNA and Human Evolution. Nature (325): 31-36.

Eggers, Hans-Jürgen 1959. Einführung in die Vorgeschichte. Piper: München.

$\mathrm{Fu}$, Qiaomei et al. 2016. The Genetic History of Ice Age Europe. Nature (534): 200-205.

Furholt, Martin 2017. Massive Migrations? The Impact of Recent aDNA Studies on our View of Third Millennium Europe. European Journal of Archaeology: 1-33.

Gamba, Cristina et al. 2014. Genome Flux and Stasis in a five Millennium Transect of European Prehistory. Nature Communications (5): 5257.

Grünert, Heinz 2002. Gustaf Kossinna (1858-1931): vom Germanisten zum Prähistoriker. Ein Wissenschaftler im Kaiserreich und in der Weimarer Republik. Rahden: Westfalen.

Haak, Wolfgang et al. 2015. Massive Migration from the Steppe was a Source for Indo-European Languages in Europe. Nature (522): 207-211. 
Hansen, Svend und Johannes Müller 2011. Sozialarchäologische Perspektiven: Gesellschaftlicher Wandel 5000-1500 v. Chr. zwischen Atlantik und Kaukasus. Tagung Kiel 2007. Philipp von Zabern: Mainz.

Jeong, Choonwon et al. 2018. Characterizing the Genetic History of Admixture across Inner Eurasia. bioRxiv. URL: https://www.biorxiv.org/content/early/2018/05/23/327122.abstract (28.06.2018).

Jobling, Mark A. et al. 2013. Human Evolutionary Genetics. Origins, Peoples \& Disease. Taylor \& Francis Group: New York.

Jones, Eppie R. et al. 2015. Upper Palaeolithic Genomes Reveal Deep Roots of modern Eurasians. Nature Communications (6): 8912.

Kossinna, Gustaf 1911. Die Herkunft der Germanen. Zur Methode der Siedlungsarchäologie. Curt Krabitzsch: Würzburg.

Kristiansen, Kristian 2014. Towards a new Paradigm? The third Science Revolution and its possible Consequences in Archaeology. Current Swedish Archaeology (22): 11-34.

Lazaridis, Iosif et al. 2016. Genomic Insights into the Origin of Farming in the Ancient Near East. Nature (536): 419-424.

Lazaridis, Iosif et al. 2014. Ancient Human Genomes Suggest three Ancestral Populations for present-day Europeans. Nature (513): 409-413.

Leslie, Stephen et al. 2015. The Fine-Scale Genetic Structure of the British Population. Nature (519): 309-314.

Lipson, Mark et al. 2017. Parallel Palaeogenomic Transects Reveal Complex Genetic History of Early European Farmers. Nature (551): 368-327.

Mathieson, Iain et al. 2015. Genome-wide Patterns of Selection in 230 Ancient Eurasians. Nature (528): 499-503.

Metzker, Michael L. 2010. Sequencing Technologies - The next Generation. Nature Reviews Genetics (11): 31-46.

Narasimhan, Vagheesh M. et al. 2017. Estimating the Human Mutation Rate from Autozygous Segments Reveals Population Differences in Human Mutational Processes. Nature Communications (1/8): 303.

Novembre, John et al. 2008. Genes Mirror Geography within Europe. Nature (456): 98-101.

Mathieson, Iain und David Reich 2017. Differences in the Rare Variant Spectrum among Human Populations. PLoS Genetics 13 (2). URL: https://doi.org/10.1371/journal. pgen.1006581 (28.06.2018).

Olalde, Iñigo et al. 2018. The Beaker Phenomenon and the Genomic Transformation of Northwest Europe. Nature (555): 190-196.

Pacifici, Michela et al. 2013. Generation Length for Mammals. Nature Conservation (5): 89-94.

Pickrell, Joseph K. und David Reich 2014. Toward a new History and Geography of Human Genes Informed by Ancient DNA. Trends in Genetics (30): 377-389.

Posth, Cosimo et al. 2018. Language Continuity despite Population Replacement in Remote Oceania. Nature Ecology \& Evolution (4/2): 731-740.

Ralph, Peter und Graham Coop 2013. The Geography of Recent Genetic Ancestry across Europe. Public Library of Science Biology (11). URL: http://journals.plos.org/plosbiology/ article?id=10.1371/journal.pbio.1001555 (28.06.2018).

Schiffels, Stephan et al. 2016. Iron Age and Anglo-Saxon Genomes from East England Reveal British Migration History. Nature Communications (7): 10408.

Schiffels, Stephan und Duncan Sayer 2017. Investigating Anglo-Saxon Migration History with Ancient and Modern DNA. In: Harald Meller et al. (Hg.). Migration und Integration von der Urgeschichte bis zum Mittelalter. 9. Mitteldeutscher Archäologentag vom 20. bis 22. Oktober 2016 in Halle (Saale) (Tagungen des Landesmuseums für Vorgeschichte Halle, Saale 17). Landesamt für Denkmalpflege und Archäologie Sachsen-Anhalt, Landesmuseum für Vorgeschichte: Halle (Saale): 255-266.

Skoglund, Pontus und Iain Mathieson 2018. Ancient Human Genomics: The First Decade. Annual Review of Genomics and Human Genetics (19): URL: https://doi.org/10.1146/ annurev-genom-083117-021749 (28.06.2018). 
The 1000 Genomes Project Consortium 2015. A Global Reference for Human Genetic Variation. Nature (526): 68-74.

Skoglund, Pontus et al. 2016. Genomic Insights into the Peopling of the Southwest Pacific. Nature (538): 510-513.

Zuckerkandl, Emile und Linus Pauling 1965. Molecules as Documents of Evolutionary History. Journal of Theoretical Biology (8): 357-366.

Wolfgang Haak \& Stephan Schiffels

Department of Archaeogenetics

Max Planck Institute for the Science of Human History

Kahlaische Strasse 10

07745 Jena

Deutschland

haak@sh.mpg.de

schiffels@shh.mpg.de 


\section{Kommentare}

\section{Big Picture? Anmerkungen zu DNA-Analysen und historischen Fragestellungen}

\section{Mischa Meier und Steffen Patzold}

Die Geschichtswissenschaft hat einen komplexen Untersuchungsgegenstand: Sie erforscht Menschen und ihr Handeln, und zwar nicht nur einzelne Menschen, sondern auch Gruppen und Gesellschaften. Menschen haben eigene Interessen, sie können sich selbst und andere als Menschen beobachten und ihr Handeln deshalb auch selbst intentional steuern (jedenfalls aber beeinflussen). Darüber hinaus haben Historiker früh gelernt, dass sie stets auch sich selbst mitbeobachten müssen: Sie wissen um die Historizität ihrer eigenen Wissenschaft. Und Historiker reflektieren auch, dass die Präsentation ihrer Ergebnisse - die historische Erzählung - spezifischen historischen Kontexten und eigenen sprachlichen Regeln unterliegt.

Historische DNA ist im Vergleich dazu ein deutlich weniger komplexer Untersuchungsgegenstand. Denn Genetiker beobachten (leider) ihr eigenes Tun nicht fortwährend als Teil der Geschichte; und sie reflektieren in ihren Veröffentlichungen auch nicht in hinreichendem Maße die wissenschaftlichen Folgen der sprachlichen Regeln, die die Darbietung ihrer Ergebnisse rahmen. Vor allem aber hat DNA keine eigenen Interessen, sie beobachtet sich nicht selbst, und sie kann ihr eigenes Handeln nicht intentional steuern. Aus der Perspektive der Geschichtswissenschaft lässt sie sich deshalb vergleichsweise leicht untersuchen. Es steht zwar außer Frage, dass die DNA in irgendeiner Weise menschliches Handeln von Ferne mitbeeinflusst; niemand aber kann seriös behaupten, dass allein die Analyse von DNA das Handeln eines Menschen in einer historischen Situation schlüssig begründen könnte. Die Kenntnis der DNA längst verstorbener Menschen erklärt deshalb historisch zunächst einmal gar nichts: Sie bedarf - wie alle anderen historischen Daten auch - der Interpretation. Die Verfahren, mit denen aus diesen Daten Geschichte gemacht wird, sollten mindestens so komplex sein wie diejenigen, die heute als Standard in der Geschichtswissenschaft etabliert sind.

Diese hat als Disziplin niemals dadurch wichtige Impulse erfahren, dass sich schlicht ihre Datenbasis erweitert hätte, sondern dadurch, dass die Verfahren komplexer werden, mit denen Historiker aus diesen Daten Geschichte herstellen. Zentral waren dabei in den letzten Jahrzehnten folgende drei Entwicklungen: Historiker haben erstens im Zuge des linguistic turn reflektiert, wie sehr Sprache Gesellschaften beeinflusst - und zugleich 
Sprache als Leitmodell für ihre Analyse sozialer Einheiten genutzt. Historiker haben zweitens sozial- und kulturwissenschaftliche Theorien der Praxis aufgegriffen und für die Analyse historischer Daten ummodelliert. Und sie haben drittens aus den Erfahrungen der Globalisierung heraus begonnen, ihr Fach aus dem nationalen Gehäuse zu befreien, Europa zu dezentrieren und Geschichten globaler Verflechtungen zu erzählen. Die Analyse historischer DNA erweitert zwar in willkommener Weise die Datenbasis der Geschichtswissenschaft (zumal für Regionen und Zeiten, die vergleichsweise arm an anderen historischen Daten sind). Sie hat aber, da sie keine neuen geschichtswissenschaftlichen Verfahren generiert, keinerlei Potential, die Disziplin als solche zu verändern. Das zeigt sich übrigens schon darin, dass die Debatte über alte DNA in der Geschichtswissenschaft im Grunde nur dort geführt wird, wo andere historische Daten vergleichsweise rar sind. Für die Geschichte des Ersten oder Zweiten Weltkriegs etwa oder der Dekolonisierung Afrikas im 20. Jahrhundert sind DNA-Analysen heute schlicht irrelevant.

Vor diesem Hintergrund gilt es nun zu evaluieren, welches Angebot Schiffels und Haak für Historiker bereithalten, die sich für die Geschichte der sogenannten Völkerwanderungszeit interessieren, genauer: für das Ende der römischen Herrschaft in Britannien und die frühe Geschichte der Angelsachsen.

Als Historiker beobachten wir schon seit gut 15 Jahren, dass genetische Untersuchungen immer von neuem behaupten, nun endlich das big picture zweifelsfrei ermittelt zu haben - nicht nur, aber gerade auch für das angelsächsische Britannien. Allerdings kommen einschlägige Studien jeweils zu ganz unterschiedlichen, teils geradezu konträren Ergebnissen (Bos et al. 2011, 2012). ${ }^{1}$ Schon dies belegt, dass die naturwissenschaftlichen Methoden eben keineswegs erlauben, die historische ,Wahrheit' zu ermitteln, sondern ebenfalls nur zu Thesen führen, die auf der Interpretation von Daten beruhen. Als Historiker sind wir gut beraten, die neuen Daten zur Kenntnis zu nehmen. Wir dürfen aber nicht die vielfach gegenläufigen Interpretationen kritiklos akzeptieren. Dies gilt auch für die Thesen, die Schiffels und Haak hier zur Diskussion stellen: Sie sind lediglich ein weiteres Angebot in der Reihe immer neuer Thesen, die einander teils widersprechen, jeweils für sich aber als naturwissenschaftlich ,bewiesen' präsentiert werden.

Hinzu kommt: Schiffels und Haak haben die naturwissenschaftliche Analyse der erhobenen Daten dazu genutzt, eine Frage zu beantworten, die für die Geschichtswissenschaft uninteressant ist. Historiker interessieren sich nicht dafür, wieviel Prozent der heutigen Bevölkerung Großbritanniens angelsächsische Vorfahren haben. Diese Zahl wäre für uns nur dann interessant, wenn der exakte Anteil angelsächsischer Vorfahren in irgendeiner Weise das Handeln der Menschen in Großbritannien beeinflussen (und 
damit historisch erklären) könnte. Ob der Anteil der Briten mit angelsächsischen Vorfahren in Ostengland bei zwölf, 38 oder 73 Prozent liegt, ändert aber an ihren Entscheidungen mit Blick auf den Brexit, an der Wahl ihres Fußballvereins, ihren beruflichen Karrierechancen oder ihrem gesellschaftlichen Status nichts. Solche Zahlen mögen allenfalls in aktuellen politischen Identitätsdebatten verfangen, in denen Identität verkürzend am genetischen Material festgemacht wird. Die historische Identitätsforschung hat indes mittlerweile einen weitaus höheren Grad an Komplexität erreicht.

In der Studie, die ihren hiesigen Ausführungen zugrunde liegt (Schiffels et al. 2016: 10408), behaupten Schiffels und Haak - den Gepflogenheiten naturwissenschaftlicher Journale entsprechend -, ihre „, analysis of early and middle Anglo-Saxon samples from East England adds significantly to our picture of the Anglo-Saxon period in Britain“. Ihre Kernthesen lauten: 1) Die untersuchten vier Individuen von einem Friedhof in Oakington bei Cambridge seien kulturell als Angelsachsen anzusprechen, genetisch aber gemischt. 2) Neue Immigranten in Britannien seien „frequently poorer" als die Personen „of native British ancestry“ gewesen. 3) Der Vergleich zwischen Proben aus Oakington und Hinxton (wo die untersuchten Inidividuen genetisch „unmixed“ seien) „shows that early medieval migration took a variety of forms and that these migrants integrated with the incumbent population in different ways". Aus der Perspektive der Historiker ist nun zu evaluieren, worin der Erkenntnisgewinn dieser drei Thesen konkret besteht.

$\mathrm{Zu}$ 1) Die Einordnung der vier Individuen aus Oakington als Angelsachsen beruht nicht auf naturwissenschaftlichen Methoden, sondern auf der ethnischen Interpretation von Grabbeigaben - ein Verfahren, das in der Archäologie mittlerweile zutiefst umstritten ist und in jüngeren Studien mit guten Gründen kaum mehr angewendet wird (grundlegend Brather 2000 \& 2004; Halsall 2007). Das bedeutet: Wir können gar nicht sagen, ob die vier Individuen, die Schiffels und Haak genetisch untersucht haben, Angelsachsen waren. Aber selbst wenn wir das einmal (weil es angesichts von Zeit und Raum historisch nicht unplausibel ist) annehmen wollen: Ein ApartheidSystem in der angelsächsischen Welt, gegen das Schiffels und Haak hier argumentieren, hat in der historischen Zunft der vergangenen Jahrzehnte ohnehin niemand angenommen. ${ }^{2}$

$\mathrm{Zu}$ 2) Die These beruht einmal mehr auf der ethnischen Interpretation von Grabbeigaben (hier konkret einer kreuzförmigen Fibel). Sie postuliert zudem, dass es einen direkten Zusammenhang zwischen der Fülle an Grabbeigaben und dem sozialen Status und dem Reichtum der bestatteten Individuen zu deren Lebzeiten gegeben habe. Auch dies wird, ebenso wie im Übrigen eventuelle Zusammenhänge zwischen Knochenbeschaffenheit und sozialem Status, in der Archäologie mittlerweile erheblich differenzierter diskutiert: Grabbeigaben spiegeln nicht ungebrochen den sozialen Sta- 
tus der bestatteten Person wider. ${ }^{3}$ Vor allem aber beruht die These, soweit sie nicht aus der Literatur geschöpft ist, auf der Beobachtung genau zweier (!) Gräber eines einzigen Gräberfelds in Oakington. Es fällt dem Historiker schwer, aus dieser Materialbasis auf ein häufiges Phänomen in Ostengland zu folgern. Schiffels und Haak haben im vorliegenden Beitrag zwar zu Recht das Problem der Repräsentativität kleiner Samples angesprochen und auf die Chancen der Untersuchung ganzer Genome hingewiesen. Zu ihrer historischen These über die materielle Ausstattung neu Eingewanderter trägt aber die Untersuchung des Genoms nichts bei. Deshalb bleibt die kleine Zahl der untersuchten Individuen für diese These ein methodisches Problem.

Zu 3) Der Historiker wird der dritten These, die Schiffels und Haak vorgetragen haben, ohne Weiteres zustimmen können. Er hätte allerdings spätestens nach den interdisziplinären Forschungen zur Transformation of the Roman World seit den 1990er Jahren auch gar nichts anderes erwartet. Ganz im Gegenteil: Wir rechnen auf der Basis unserer schriftlichen und archäologischen Überlieferung eher mit noch größerer Differenzierung und Heterogenität, sobald wir auch genetische Daten aus Wales, Südwestengland, den Midlands mit einbringen können. Im Übrigen wird man aber methodisch zu bedenken geben, dass Schiffels und Haak aus dem Friedhof in Hinxton gerade einmal drei Individuen untersucht haben, deren Datierungen sich zudem deutlich überschneiden. Der Eindruck einer unmixed Gruppe könnte deshalb auch schlicht durch das kleine Sample entstanden sein. Wichtig wäre es jedenfalls, die Gesamtzahl der Gräber in Hinxton, die geschätzte Gesamtbevölkerung der Region, aber auch die konkrete Lage der Gräber in Hinxton zueinander zu kennen. Handelte es sich bei den untersuchten Individuen vielleicht sogar um eine Familie oder Verwandtschaftsgruppe?

Als Historiker können wir in diesen Thesen keine grundlegend neuen Erkenntnisse und auch keinen bedeutenden Beitrag zu unserem Bild der angelsächsischen Periode Britanniens sehen. Das historische big picture der Geschichte Britanniens oder der sogenannten „Völkerwanderung“, um das es Schiffels und Haak zu tun ist, verändert sich durch ihre genetische Forschung jedenfalls nicht. Stattdessen verheißen ihre Untersuchungen (und weitere Studien solcher Art) jedoch einen Erkenntnisgewinn für die Mikroebene, die Historiker übrigens schon seit Jahrzehnten genauso zu schätzen wissen wie das Große und Ganze. Möglichst flächendeckende genetische Analysen zu einem Gräberfeld könnten, klug kombiniert mit archäologischen Befunden, hochinteressante Daten für eine Mikrogeschichte der dort angesiedelten lokalen Gesellschaft bieten. Sie versprechen zum Beispiel wichtige Aufschlüsse zu konkreten Verwandtschaftsverhältnissen und deren Niederschlag in der Bestattungspraxis, zur gender history vor Ort, auch zu Fragen von Endogamie und Exogamie lokaler Gruppen. All 
das setzt allerdings voraus, dass im Hintergrund der Interpretation der Daten nicht mehr Fragen und Deutungsmodelle des 19. Jahrhunderts stehen. Eine solche Konzentration auf die Mikroebene könnte mancher genetischer Studie zwar einen Teil ihrer öffentlichen Wirksamkeit nehmen; es würde sie aber für Historiker zu einem ernstzunehmenden wissenschaftlichen Beitrag zur Geschichte Europas aufwerten. Die Genetik hat das Potential, in diesem Sinne - als Zulieferin von Daten auf lokaler Ebene - zu einer interessanten neuen historischen Hilfswissenschaft für bestimmte, sonst quellenarme Phasen der Geschichte zu avancieren. Die Interpretation der Daten aber und die Bildung von Thesen zur Geschichte sind ein komplexes Geschäft, das theoretische Reflexion und den Umgang mit eigenen anspruchsvollen Methoden erfordert. Dies ist und bleibt die Aufgabe der Geschichtswissenschaft.

\section{Anmerkungen}

1 Vgl. zum Beispiel die gegenläufige Einschätzung der Justinianischen Pest in ihrem Verhältnis zum Erreger der spätmittelalterlichen Pest bei Bos et al. 2011: 509: „This further questions the aetiology of the sixth to eighth century Plague of Justinian, popularly assumed to have resulted from the same pathogene: our temporal estimates imply that the pandemic was either caused by a Y. pestis variant that is distinct from all currently circulating strants commonly associated with human infections, or it was another disease altogether." Anders Bos et al. 2012: „The inclusion of this additional data reveals a cluster of $Y$. pestis strains that diverge at a time significantly in advance of the Black Death, with divergence dates roughly coincident with the Plague of Justinian (6th to 8th century AD).“

2 Der von Schiffels und Haak zitierte Beitrag von Thomas et al. 2006 ist für die historische Forschung zum angelsächsischen Britannien irrelevant geblieben.

3 Vgl. statt anderer schon Halsall 1995; an einem prominenten Beispiel Halsall 2010.

\section{Literatur}

Bos, Kirsten I. et al. 2011. A draft Genome of Yersinia Pestis from Victims of the Black Death. Nature (478): 506-510.

Bos, Kirsten I. et al. 2012. Yersinia Pestis: New Evidence for an Old Infection. PLoS ONE 7 (11): e49803.

Brather, Sebastian 2000. Ethnische Identitäten als Konstrukte der Frühgeschichtlichen Archäologie. Germania (78): 139-177.

Brather, Sebastian 2004. Ethnische Interpretationen in der frühgeschichtlichen Archäologie. Geschichte Grundlagen und Alternativen. Berlin: de Gruyter.

Halsall, Guy 2007. Barbarian Migrations and the Roman West, 376-568. Cambridge: Cambridge University Press.

Halsall, Guy 2010. Childeric's Grave, Clovis' Succession, and the Origins of the Merovingian Kingdom. In: Halsall, Guy (Hg.). Cemeteries and Society in Merovingian Gaul. Selected Studies in History and Archaeology, 1992-2009. Leiden: Brill: 169-187. 
Schiffels, Stephan et al. 2016. Iron Age and Anglo-Saxon Genomes From East England Reveal British Migration History. Nature Communications (7): 10408.

Thomas, Mark G., Michael P. H. Stumpf und Heinrich Härke 2006. Evidence for an apartheidlike Social Structure in early Anglo-Saxon England. Proceedings of the Royal Society, Biological Sciences (273): 2651-2657.

Mischa Meier

Seminar für Alte Geschichte

Universität Tübingen

Wilhelmstr. 36

72074 Tübingen

Deutschland

mischa.meier@uni-tuebingen.de

Steffen Patzold

Seminar für Mittelalterliche Geschichte

Universität Tübingen

Wilhelmstr. 36

72074 Tübingen

Deutschland

Steffen.patzold@uni-tuebingen.de 


\section{Geistlose Geschichte oder histo- risierte Genetik? Überlegungen eines „Gatekeepers"}

Jan Keupp

Parzivals Halbbruder Feirefiz führt im Roman des Wolfram von Eschenbach eine hybride Existenz: Gescheckt wie das Federkleid einer Elster wirkt seine äußere Erscheinung. Denn Haut und Haar schimmern dem Kind eines französischen Königssohns und einer orientalischen Monarchin in strahlendem Weiß und tiefstem Schwarz (Schuler-Lang 2014: 212 ff.). Hält mit dieser fiktiven Gestalt die Genetik Einzug in mittelalterliche Gefilde? Sicherlich nicht ihre moderne Spielart, allenfalls deren mittelalterliche Schwester. Wiewohl im Roman als „Wunderwerk Gottes“ bezeichnet, ist die Figur des Grenzgängers Feirefiz das Geschöpf einer höchst irdischen und vor allem zeitspezifischen genealogischen Konstruktion, geschaffen nach einer eigenwilligen Vererbungslehre. Dass „Hybriden [...] nicht die genaue Mittelform zwischen den Stammarten darstellen" (Mendel 1866: 10) - diese experimentell gewonnene Erkenntnis Gregor Mendels war der mittelalterlichen Vorstellungswelt ebenso fremd wie die Codierung von Erbinformationen in Nukleotidsequenzen. Wenn Feirefiz wegen seiner weißen Haut von der Mutter geküsst und von den „Heiden“ verehrt wird, beziehen sich diese Reaktionen rein auf phänotypisch erfahrbare Merkmale. Und diese legen das Handeln des hybriden Helden niemals deterministisch fest, der als Heidenkönig, Minneritter und Gralshüter begegnet.

Als geschichtswirksame Kräfte scheiden Gene und Genetik demnach aus, sie verblieben konsequent unterhalb des Horizonts sinnstrukturierter Weltwahrnehmung. So jedenfalls könnte man von einem sozialkonstruktivistischen Standpunkt aus argumentieren. Als Kronzeuge dieser Sichtweise ließe sich der Soziologe Bruno Latour aufrufen: Die Aussage eines modernen Wissenschaftlerteams, der ägyptische Pharao Ramses II. sei einem Tuberkuloseerreger erlegen, weist er als Anachronismus zurück: Wie hätte dies im vorchristlichen 13. Jahrhundert geschehen können, wenn doch das Bakterium erst im Jahr 1882 durch Robert Koch entdeckt und beschrieben wurde (Latour 2000)? Latour leugnet weder Krankheit noch Tod des Königs. Doch müsse ein Mikroorganismus, der erst durch die labortechnischen Verfahren der Moderne sichtbar gemacht werden konnte, im Pharaonenreich als ebenso ahistorisch gelten wie etwa ein Maschinengewehr oder ein marxistisch motiviertes Attentat. Die Pressemeldung über den Tuber- 
kulosetod des antiken Herrschers markiere folglich ein verfehltes Verständnis von der Faktizität naturwissenschaftlicher Feststellungen: Wie in einer Zeitkapsel eingeschlossen würden sie - einmal in die Welt gesetzt - aus dem historischen Ereignisfluss ausgesondert. Geschichte sei in dieser Sicht lediglich der zeitspezifisch missverstandene Zugriff der Menschen auf das Reich der ,objektiv' unabänderlichen Natur. Als Akteure seiner Netzwerke möchte Latour demgegenüber nur solche Entitäten zulassen, die im Handeln Dritter „einen Unterschied“ machen (Latour 2007: 123), denn „Unterschiede sind alles, was wir zunächst brauchen, um eine lebhafte Geschichtlichkeit in Bewegung zu setzen“ (Latour 2002: 181).

\section{Historisierung: Eine ,Unvollendete' des 19. Jahrhunderts}

Sind Gene damit als Gegenstand der Geschichtsforschung generell unerheblich? Sicher nicht! Latours Einwurf ist zu Unrecht als Gegenposition zum empirischen Realismus aufgefasst worden (Boghossian 2013: 33f.). Aus der Sicht meiner Disziplin fordert er hingegen lediglich die konsequente Fortsetzung jenes Projekts einer „universalen Historisierung alles dessen, was ist“, die als prägendes Merkmal der Wissenschaftskultur des 19. Jahrhunderts eines der „konstitutiven Kennzeichen der Moderne überhaupt“ darstellt (Oexle 1996: $10 \mathrm{f}$.). Das hehre Ziel des Historismus, die Überwindung jener „doppelte[n] Realität“, die „zwischen historischer und überhistorischer Wirklichkeit trennt" (Muhlack 1991: 20), erfuhr allerdings noch in seiner Formierungsphase eine gravierende Einengung. Der Methodenstreit mit einer mechanistisch angelegten Naturforschung mündete in eine schismatische Aufspaltung der wissenschaftlichen Interessenssphären: „Nur was Menschengeist und Menschenhand geprägt“, so propagierte es die Historik Johann Gustav Droysens, „ist Stoff zum Forschen, ist Geschichte“ (Droysen 1858: 8). Denn während die Natur mit Blick auf „das im Wechsel Gleiche“ zu erforschen sei, müsse für all jenes, das nicht der zeitlosen „Mechanik der Atome“ unterliege, „andere Erkenntnisformen gefunden werden“ (Droysen 1977: 5). Dieser auf breiter Front vollzogene Rückzug in das Reservat des menschlichen Denkens sorgte dafür, dass die Geisteswissenschaften sich als „selbständiges Ganzes neben den Naturwissenschaften“ (Dilthey 1990: 4) konstituierten. Mag es sich auch um eine „Primitivform eines bloßen Duals“ (Luhmann 1992: 462) handeln, in den disziplinären Traditionen wirkte diese Trennlinie geradezu dogmatisch fort (Oexle 1998). Zwar lassen sich in der Wissenschaftsgeschichte mehrfach Phasen der Annäherung ausmachen, wenn etwa die westdeutsche Strukturgeschichte die Frage aufwarf, ob die kulturelle Evolution des Menschen nicht als „Fortsetzung der Naturent- 
wicklung" (Conze 1986: 28) eines gewandelten Methodeninstrumentariums bedürfe. Gerade die Hinwendung der Historischen Sozialforschung zu „erklärenden“ Makromodellen führte aber nicht „zum Überschreiten hergebrachter Hemmungen“ (ebd.), sondern sorgte durch ihren Abstraktionsgrad dafür, dass ihr seitens der „Neuen Kulturgeschichte“ schon bald „der Wind [...] frontal ins Gesicht" (Kocka 2000: 11) blies. Statt statische Strukturmodelle zu entwickeln schärfte sie den Blick für die Kontingenz und Multiperspektivität historischen Geschehens.

Der auf breiter Front vollzogene Kurswechsel mit seiner Konzentration auf das „selbstgesponnene Bedeutungsgewebe“ (Geertz 1983: 9) des Menschen verband sich mit der Forderung nach einer „Kulturalisierung der $\mathrm{Na}$ tur“, lehnte aber umgekehrt eine „Naturalisierung der Kultur“ kategorisch ab (Köchy 2011). Bruno Latours Einspruch richtet sich zu Recht gegen einen solchen Rückfall in Rhetoriken disziplinärer Abschottung. Sein programmatischer Historisierungsappell zielt hingegen auf die Aufgabe altüberkommener Polaritäten, indem er Phänomene von Kultur und Natur symmetrisch auf ihre Handlungswirksamkeit hin befragt. Dieser Analyseansatz lässt sich jenem Set theoretischer Zugriffsweisen zuordnen, die derzeit unter der Sammelbezeichnung „Praxistheorien“ firmieren. Sie sehen die Dichotomie zwischen sozial konstruiertem Sinn und natürlich-materiellem Sein im konkret vollzogenen Umgang mit den physischen und psychischen Artefakten der Umwelt aufgehoben. Praxistheorien stellen somit einen vielversprechenden Schlüssel zur geschichtswissenschaftlichen Betrachtung genetischer Befunde dar: Denn wer würde leugnen wollten, dass die heute sichtbar gemachten Gensequenzen, wenn nicht aktive Partizipanten, so doch (auch) Produkte konkreter historischer Praktiken darstellen, etwa von Familienorganisation, Heiratsstrategien oder Migration. So wenig paläogenetische Analyse demnach zur menschlichen "Geistesgeschichte“ beizutragen hat, so sehr kann sie unser gegenwärtiges Ringen um eine Rekonstruktion historischer Geschehenshorizonte bereichern.

Diese fachhistorische Selbstbespiegelung mag dazu beitragen, Schnittmengen zwischen Paläogenetik und Geschichtswissenschaft zu markieren. Sie werden umso größer ausfallen, je stärker beide Disziplinen 1) die epistemologischen Grenzen der von ihnen bearbeiteten Quellengattungen beachten (siehe die Stellungnahmen von Maier/Patzold, Rummel und Feuchter) und 2) in ihrem Streben nach Historizität konvergieren. Insofern sehe ich gerade keinen „gefährlichen Einbruch der Genetik in die Mediävistik“ (Bösl 2017a: 130), sondern einen klaren gemeinsamen Arbeitsauftrag. Gleichwohl möchte ich die Rolle eines „Gatekeepers“, die mir in der zurückliegenden Debatte zugeschrieben worden ist (Bösl 2017b: 12), im Hinblick auf die letztgenannte Kondition dankbar annehmen. 


\section{Geschichte nach Gesetzmäßigkeiten?}

Eine „verworrene und anarchische Erscheinung“ böte die Geschichte, so äußerte der englische Privatgelehrte Henry Thomas Buckle 1860. Es sei endlich an der Zeit, sie gleich der Natur „unwandelbaren und allgemeinen Gesetzen" zu unterwerfen (Buckle 1860: 5, vgl. Mehr 2009). Sein Werk steht an der Schwelle der endgültigen Trennung von Natur- und Geisteswissenschaft und man wird im Rückblick auf die heftigen Reaktionen nicht fehlgehen, in ihm einen maßgeblichen Scheidungsgrund zu sehen. Denn die Suche nach zeitlos-objektiver Regelhaftigkeit ist mit dem Streben nach universaler Historisierung von Kultur und Natur damals wie heute unvereinbar.

Daraus begründet sich mein Abwehrreflex gegenüber jener Spielart der genetic history, die am Jenaer MPI unter dem Abteilungsnamen „Sprachund Kulturevolution" firmiert. Genauer gesagt solchen Studien, die es für sich in Anspruch nehmen, die mutmaßlich ,großen Fragen' der Menschheitsgeschichte in allgemeingültige Makromodelle zu überführen. Auf der Basis bioinformatischer Rechenverfahren werden kulturelle Phänomene in ihrer historischen Dimension als vermeintlich stabile Kausalrelationen abgebildet. Das auf Darwin zurückgehende Ziel, „to have a mechanistic understanding of the evolution“, wird dabei selbstbewusst auch für das „Reich der Kultur“ reklamiert (Gray \& Watts 2017: 1). Auf Basis der selektiven Variablen von Raum, politischer Organisation, Viehhaltung und Ressourcennutzung (jeweils reduziert auf eine Kennziffer) könne beispielsweise die Verbreitung des Glaubens an "moralizing high gods (MHGs)“ mit einer Verlässlichkeit von 91 Prozent rückwirkend prognostiziert werden (Botero et al. 2014). Ja, selbst treffsichere Vorhersagen über die zukünftige Entwicklung nationalstaatlicher Gemeinschaften auf dem Gebiet von Wirtschaft und Politik ließen sich mit phylogenetischen Verfahren erzielen (Matthews et al. 2016).

\section{Daten als historische Artefakte}

Wenngleich sich die statistisch-mathematischen Rechenoperationen der fachlichen Beurteilung des Historikers entziehen, sei doch zunächst auf die mehrfach eigentümliche Historizität der Datengrundlage selbst verwiesen. Historische Genese und Struktur der Datensätze sind inkonsistent (siehe: https://d-place.org). Sie erfasst europäische Gesellschaften auf dem Stand des 20. Jahrhunderts (MHGs präsent), die indigenen ,Stämme‘ Nordamerikas dagegen auf einem Zeithorizont um 1850-1870 (keine MHGs): Die Neue Welt erscheint dadurch als ,Heidenland‘. Zutreffend scheint hier zu- 
dem ein weiterer Vorbehalt der Fachhistoriker: „They regard most historical frameworks used in genetic publications as outdated" (De Chadarevian 2010: 302; siehe auch Bösl 2017b: 95; Egorova 2010: 359). Über Gesellschafts- und Glaubensformen der Niederländer sind in der genannten Studie lediglich zwei ältere Werke aus den Jahren 1939 und 1955 zu Rate gezogen worden - für die Hebräer immerhin auch die „Holy Bible“. Aber selbst dort, wo neuere Kompendien Verwendung fanden, erweist sich das empirische Substrat einer makroskopischen Modellbildung als problembehaftet: Ein rezenter Beitrag über die Entwicklung von Landbesitzformen in Südostasien (Kushnick et. al. 2014) stützt sich auf die einschlägigen Bände der Encyclopedia of World Cultures. Eine erste zufällige Stichprobe zum Lemma "Nguna“ zeigte, dass die im Aufsatz priorisierte „kin-group ownership“ keineswegs der Praxis auf der südpazifischen Insel entspricht, die von anhaltenden Konflikten um die individuelle Landnutzung gekennzeichnet ist (Facey 1991: 243). Wie die Autorin andernorts zu verstehen gibt, verbergen sich hinter den knappen Angaben des Artikels erhebliche Fallstricke ethnographischer Datenerhebung: „It was impossible to conduct any but the most general of inquiries into such subjects as land tenure and disputes without jeopardizing the entire research project" (Facey 1989: 78). Die Belastbarkeit der unter solchen Bedingungen gewonnenen Daten sinkt dramatisch. Auch meine eigene Disziplin zeigt sich weder in der Lage noch gewillt, zeitlos gesicherte Voten abzugeben. Als charakteristische Form von Landbesitz und -distribution des Karolingerreiches galt etwa bis in die 1990er Jahre das so genannte Lehnswesen, das für diese Periode mittlerweile weithin als Forschungskonstrukt gehandelt wird (Patzold 2012).

Umgekehrt werden sich Geisteswissenschaftler hüten müssen, der Anziehungskraft der „cold, hard data“ (Anonym 2016: 438) fremder Disziplinen zu erliegen, zumal diesbezügliche Sirenengesänge seriöser Molekularbiologen sich in Grenzen halten. Auch naturwissenschaftliche Daten sind Artefakte, ausgestattet mit einer historischen Dimension. Gerade in den empirischen Wissenschaften gilt es gemäß Karl Popper als Gemeinplatz, dass der „Gang der Wissenschaft [...] im Probieren, Irrtum und Weiterprobieren“ (Popper 1964: 101) besteht. Einen Musterfall hierfür bietet das im Auftaktbeitrag behandelte Beispiel der „angelsächsischen Migration“: Mustergültig scheint hier nämlich in erster Linie die kritische Selbstkontrolle einer hypothesenförmig arbeitenden Disziplin, die eigene Erträge immer wieder mit neuen Prämissen, Befunden und Gegenmodellen konfrontiert. „Eindeutig gezeigt" (Haak \& Schiffels) werden konnte in der Zusammenschau der Studien gerade nur, in welchem Maße die Hinzuziehung paläogenetischer Methoden die Komplexität der Debatte in wissenschaftlich wünschenswerter Weise steigert, statt zu einfachen, eindeutigen Antworten zu führen. 


\section{Erkenntnisziel Einzelfall}

Doch handelt es sich hier gerade nicht (nur) um ein Problem der Aggregation von big data. Mit Droysens Entgegnung auf Buckle könnten wir durchaus einräumen, dass selbst eine Studie, die empirisch „Irriges, Willkührliches, Unzulängliches in Fülle" enthalte, hinsichtlich ihrer epistemologischen Implikationen einer gesonderten Prüfung bedürfe (Droysen 1863: 4). Sind phylogenetische Modelle nicht lediglich zweckvolle Mittel, eine „denkende Ordnung der empirischen Wirklichkeit“ (Weber 1982: 150) auf zeitgemäße Weise zu gewährleisten? An diesem Punkt treten die divergierenden Erkenntnisinteressen der Disziplinen unmittelbar zu Tage: Denn gerade Max Weber bestreitet nicht die struktur- und regelgeleitete Rationalität historischen Handelns. Doch „würde der denkbar umfassendste empirisch-statistische Nachweis der Tatsache einer gesetzmäßig auftretenden Reaktion [...] hinter den Anforderungen, die wir an die Geschichte [...] stellen, der Erkenntnisqualität nach zurückbleiben“ (Weber 1985: 70, Hervorhebung im Original). Selbst gesicherte Kausalität könne niemals die Frage nach dem Warum, der subjektiven und kulturspezifischen Geschehensdeutung, beantworten, hätte also zum historischen Verständnis des jeweiligen Ereignisses schier nichts beizutragen. Es sei eben nicht Ziel der Geschichtsforschung, vom Einzelfall ausgehend zu ewig gültigen Gesetzmäßigkeiten zu gelangen, so lässt sich in gleicher Weise Hans-Georg Gadamer vernehmen: Ihr Erkenntnisinteresse strebe vielmehr dahin, die ereignishaft fassbare „Erscheinung selber in ihrer einmaligen und geschichtlichen Konkretion zu verstehen" (Gadamer 2010: 10).

Nicht zwischen ,Natur' und ,Geist' verläuft demnach die Demarkationslinie, sondern zwischen historischem und ahistorisch-überzeitlichem Erkenntnisziel. Das Jenaer Max-Planck-Institut für Menschheitsgeschichte sollte hier bereits seinem Namen nach eindeutig positioniert sein. Auf dieser Grundlage kann und wird es zum Teil jenes multidisziplinären Gemeinschaftsprojekts werden, als welches sich Geschichtsforschung seit jeher versteht.

\section{Literatur}

Boghossian, Paul 2013. Angst vor der Wahrheit. Berlin: suhrkamp.

Bösl, Elsbeth 2017a. Doing Ancient DNA. Zur Wissenschaftsgeschichte der aDNA-Forschung. NTM (25): 99-142.

Bösl, Elsbeth 2017b. Doing Ancient DNA. Zur Wissenschaftsgeschichte der aDNA-Forschung. Bielefeld: transcript. 
Botero, Carlos A. et al. 2014. The ecology of religious beliefs. Proceedings of the National Academy of Sciences of the USA (111.47): 16784-16789.

Buckle, Henry Thomas 1860. Geschichte der Civilisation in England. Bd. 1. Heidelberg/Leipzig: C.F. Winter.

Conze, Werner 1986. Evolution und Geschichte. Die doppelte Verzeitlichung des Menschen. Historische Zeitschrift (242): 1-30.

De Chadarevian, Soraya 2010. Genetic Evidence and Interpretation in History. BioSocieties (5,3): 301-305.

Dilthey, Wilhelm 1990. Einleitung in die Geisteswissenschaften. Versuch einer Grundlegung für das Studium der Gesellschaft und ihrer Geschichte. 9. Aufl. 1990. Göttingen: Vandenhoeck \& Ruprecht.

Droysen, Johann Gustav 1858. Grundriss der Historik. Jena: F. Frommann.

Droysen, Johann Gustav 1863. Die Erhebung der Geschichte zum Rang einer Wissenschaft. Historische Zeitschrift (9): 1-22.

Droysen, Johann Gustav 1977. Historik. Vorlesungen über Enzyklopädie und Methodologie der Geschichte, hrsg. von Rudolf Hübner. Stuttgart: WBG.

Egorova, Yulia 2010. DNA Evidence? The Impact of Genetic Research on Historical Debates. BioSocieties (5,3): 348-365.

Facey, Ellen E. 1989. „Blood“ and „Line“: Exploring Kinship Idioms of Nguna, Vanuatu. Culture $(9,2): 77-87$.

Facey, Ellen E. 1991. Nguna. In: Terence E. Hays (Hg.) Encyclopedia of World Cultures, Bd. 2: Oceania. New York: G. K. Hall: 242-244.

Gadamer, Hans-Georg 2010. Gesammelte Werke. Hermeneutik I. Wahrheit und Methode, 7. Aufl. Tübingen: Mohr Siebeck.

Geertz Clifford 1983. Dichte Beschreibung. Beiträge zum Verstehen kultureller Systeme. Frankfurt a. M.: suhrkamp.

Gray, Russell \& Joseph Watts 2017. Cultural Macroevolution Matters. Proceedings of the National Academy of Sciences of the USA (114,30): 7846-7852.

Köchy, Kristian 2011. Naturalisierung der Kultur oder Kulturalisierung der Natur? Zur kulturphilosophischen Abwehr der Geltungsansprüche der Naturwissenschaften. Zeitschrift für Kulturphilosophie (5,1): 137-159.

Kocka, Jürgen 2000, Historische Sozialwissenschaft heute. In: Paul Nolte et al. (Hg.). Perspektiven der Gesellschaftsgeschichte. München: C. H. Beck: 5-24.

Kushnick, Geoff, Russell Gray und Fiona Jordan 2014. The Sequential Evolution of Land Tenure Norms. Evolution and Human Behavior (35): 309-318.

Latour, Bruno 2000. On the Partial Existence of Existing and Non-existing Objects. In: Lorraine Daston (Hg.). Biographies of scientific objects. Chicago: University of Chicago Press: 247-269.

Latour, Bruno 2002. Die Hoffnung der Pandora. Untersuchungen zur Wirklichkeit der Wissenschaft. Frankfurt a. M.: suhrkamp.

Latour, Bruno 2007. Eine neue Soziologie für eine neue Gesellschaft. Einführung in die AkteurNetzwerk-Theorie. Frankfurt a. M.: suhrkamp.

Luhmann, Niklas 1992. Die Wissenschaft der Gesellschaft. Frankfurt a. M.: suhrkamp.

Matthews, Luke et al. 2016. Shared Cultural History as a Predictor of Political and Economic Changes among Nation States. PLoS One $(11,4)$.

Mehr, Christian 2009. Kultur als Naturgeschichte. Opposition oder Komplementarität zur politischen Geschichtsschreibung 1850-1890? Berlin: Akademie Verlag.

Mendel, Gregor 1866. Versuche über Pflanzen-Hybriden. Verhandlungen des Naturforschenden Vereines in Brünn (4): 3-47.

Muhlack, Ulrich 1991. Geschichtswissenschaft im Humanismus und in der Aufklärung. Die Vorgeschichte des Historismus. München: C. H. Beck.

Oexle, Otto Gerhard 1996. Geschichtswissenschaft im Zeichen des Historismus. Studien zu Problemgeschichten der Moderne. Göttingen: Vandenhoeck \& Ruprecht. 
Oexle, Otto Gerhard 1998. Naturwissenschaft und Geschichtswissenschaft. Momente einer Problemgeschichte. In: Ders. (Hg.). Naturwissenschaft, Geisteswissenschaft, Kulturwissenschaft: Einheit - Gegensatz - Komplementarität? Göttingen: Wallstein: 99-151.

Patzold, Steffen 2012. Das Lehnswesen. München: C. H. Beck.

Popper, Karl R. 1964. Naturgesetze und theoretische Systeme. In: Hans Albert (Hg.). Theorie und Realität. Tübingen: Mohr Siebeck: 87-102.

Schuler-Lang, Larissa 2014. Wildes Erzählen - Erzählen vom Wilden. ,Parzival' ,Busant' und ,Wolfdietrich $D^{\prime}$. Berlin: de Gruyter.

Anonym 2016. Source Material. Geneticists and Historians Need to Work together on Using DNA to Explore the Past. Nature (533): 437-438.

Weber, Max 1982. Gesammelte Aufsätze zur Wissenschaftslehre, hrsg. von Johannes Winckelmann. 5. Aufl. Tübingen: Mohr Siebeck.

Jan Keupp

Historisches Seminar

WWU Münster

Domplatz 20-22

48143 Münster

Deutschland

jan.keupp@uni-muenster.de 


\section{Für einen kritischen Dialog zwischen Geschichtswissenschaft und genetic history}

Jörg Feuchter

Bis vor wenigen Jahren konnte die genetic history nur uniparentale Marker verfolgen, die Aufschlüsse über jeweils nur eine Ahnenlinie gaben, und sie war ausschließlich auf die Analyse des Erbmaterials lebender Menschen angewiesen. Jetzt geht in der Tat sehr viel mehr. Dies liegt einerseits an der Technik des Next Generation Sequencing, die den genomweiten Zugriff auf die Breite der Vorfahrenschaft erlaubt. Vor allem aber liegt es an den immer besseren Erschließungsmöglichkeiten von ancient DNA (aDNA) aus Grabfunden. Diese aktuelle Entwicklung wird von Genetikern als "Revolution“ (Gibbons 2015) ihrer Forschungen gefeiert. In der Tat wird auf dieser neuen Grundlage versucht, bisher etablierte Vergangenheitsbilder umzustürzen. Das gilt sogar für die eigenen Resultate der noch so jungen Disziplin genetic history selbst.

Die jüngst erzielten technischen Erfolge sind in der Tat beindruckend. Gleichwohl sind damit die Probleme der genetic history keineswegs gelöst. Die Erschließbarkeit des alten Erbgutes bedeutet keinen unmittelbaren $\mathrm{Zu}$ griff auf die Vergangenheit, sondern nur auf eine Quelle (vgl. Bösl 2017: 350). Zwar stimmt es, was im Zusammenhang mit der genetic history gerne hervorgehoben wird: „Gene lügen nicht“ (Pietschmann 2014: 2). Aber sie sagen eben auch nichts. Selbst noch so gut erschlossenes Erbmaterial erzählt nicht von selbst die Vergangenheit. Das können nur Menschen tun, und genau wie Geschichtswissenschaftler oder Archäologen sind auch historische Genetiker deshalb immer „storytellers“, wie mancher selbst einräumt (Jobling 2010: 2). Doch über die zu interpretierende Quelle DNA besteht wegen ihrer relativen Neuheit erheblicher Verständigungsbedarf zwischen Natur- und Kulturwissenschaften. Dieser Dialog wurde bisher kaum geführt. Die aktuell ausgerufene „aDNA-Revolution“ macht ihn keineswegs weniger wichtig, sondern nötiger denn je. Auch die Historiker müssen sich ihm stellen, gerade auch hier in Deutschland, wo mit dem MPI für Menschheitsgeschichte in Jena eines der wichtigsten Zentren der genetic history bzw. Archäogenetik eingerichtet wurde.

Haak und Schiffels, die beide an diesem MPI wirken, ist zuzustimmen, dass es in diesem erst beginnenden Gespräch zahlreiche konzeptuelle Missverständnisse zwischen den Disziplinen gibt. Gerade für den von ih- 
nen genannten Begriff "Migration“ ist das offensichtlich (ausführlich dazu Feuchter 2017: 350-356). Übereinstimmung herrscht immerhin darin, dass Migrationen ein wichtiger historischer Faktor sind, gelten sie doch etwa in der aktuellen Mediävistik als wohl wichtigster Prozess, der kulturelle Verflechtungen bewirkte. Es herrscht hier also keineswegs eine Einstellung des Antimigrationismus. Dennoch gibt es gewaltige Differenzen. Denn Geisteswissenschaftler gehen von einer vor allem kulturell hergestellten, kaum biologisch determinierten Identität von Menschengruppen aus. Humane Identitäten werden zudem als multipel angesehen, das heißt Menschen gelten stets als durch mehrere Zugehörigkeiten bestimmt, nicht nur durch eine (noch dazu sehr eng gefasste) ethnische. Die genetic history dagegen beschäftigt sich mit einer in einer biologischen Materialität erschließbaren Abstammungsidentität der „Fortpflanzungsgemeinschaft“ (Haak \& Schiffels), die sie mit kulturellen Identitäten möglichst eng zu verknüpfen sucht, um sie historisch (und oft auch im Kontext heutiger Identitätsdiskurse) relevant zu deuten. Sie ist daher auf die problematische Gleichung „Pots = People“ doch mehr oder weniger unmittelbar angewiesen. Der erste von Haak und Schiffels angeführte Fall ist ein Musterbeispiel dafür und zugleich auch für den revolutionären Anspruch der neuen genetic history.

Bereits seit mehreren Jahren beschäftigt sich die Genetik mit der Jungsteinzeit (vgl. Bösl 2017: 327-333). In den letzten Jahren wurden immer höhere Zahlen von Skeletten aus Europa erfolgreich auf aDNA beprobt. Dabei wurden teils erhebliche genetische Diskontinuitäten festgestellt. Eine von Haak maßgeblich geleitete Studie (Haak et al. 2015) schlägt hierfür nun eine Lösung vor: In der Mitte des dritten Jahrtausends vor Christus sei eine bisher unbekannte Bevölkerung von Osten nach Europa eingewandert und habe in weiten Gebieten Ost- und Mitteleuropas die bis dahin vorfindliche Population fast völlig verdrängt. Diese neue Gruppe weise eine überaus hohe genetische Übereinstimmung mit DNA aus Gräbern der JamnajaKultur auf, die um diese Zeit und davor unter anderem im nordöstlichen Schwarzmeergebiet dominant war, weshalb von einer Migration aus diesem Raum auszugehen sei.

Dieser Befund ist bereits deshalb revolutionär, weil man bisher nur von zwei jungsteinzeitlichen Großpopulationen in Europa ausging: Zum einen von einer vorfindlichen Bevölkerung von nomadischen Jägern und Sammlern, zum anderen von sesshaften Hirten und Ackerbauern, die über Anatolien und den Balkan hinzukamen und das Nomadentum als Kulturform oder sogar die gesamte Nomadenbevölkerung rasch an den Rand drängten. Die jetzt genetisch erschlossene östliche Masseneinwanderung stürzt das gesamte Bild um. Die Studie geht aber noch viel weiter. Denn sie verknüpft die Migration aus der eurasischen Steppe mit einer der bekanntesten kulturellen Wandlungen, dem Einzug der indoeuropäischen Sprachfamilie 
nach Europa. Dies schließt an die bekannte Kurgan-Hypothese an. Neu ist aber, dass diese Sprachwanderung mit einer extrem weitgehenden Bevölkerungsverdrängung durch die neue Jamnaja-Gruppe einhergegangen sein soll, zumindest in manchen europäischen Regionen. Bemerkenswert ist auch, dass die heutigen Archäogenetiker damit in Widerspruch zu ihren eigenen Vorgängern treten. Diese hatten vor zwei Jahrzehnten nämlich Belege gerade für die Alternative zur Kurgan-Hypothese geliefert, die Ankunft des Indoeuropäischen via Anatolien in Verbindung mit der Einführung des Ackerbaus. Es war dann auch einer der maßgeblich für diese Hypothese stehenden Archäologen, welcher zur Jahrtausendwende das Zeitalter der Archäogenetik im Sinne einer interdisziplinären Synthese ausrief (Renfrew 2000). Es entbehrt nicht einer gewissen Ironie, dass nun eine genau so benannte Abteilung des Jenaer MPI für Menschheitsgeschichte antritt, Renfrews Anatolien-Hypothese zu entkräften.

Die Jenaer Studie wagt dabei sogar ganz konkrete Schlüsse, wer die ersten Indoeuropäer in Europa waren. Sie identifizieren die genetisch den Jamnaja so nahen Ost-Einwanderer nämlich mit einer bestimmten archäologischen Fundkultur, der sogenannten Schnurkeramik. Neben der Pots/ People-Problematik stellt sich hier auch die Frage nach der empirischen Basis der Zuordnung. Denn diese besteht nur aus sehr wenigen Individuen aus entsprechend ausgestatteten Gräbern. Diese sind zwar tatsächlich in der untersuchten chronologischen Reihe von rund zweihundert auf ihre DNA beprobten Individuen zwischen 6500 und 300 vor Christus die ersten in Europa, bei denen sich ein massiver genetischer Anteil an Jamnajaähnlichem Erbgut finden lässt. Doch stammen sie allesamt aus einem einzigen Gräberfeld in Esperstedt (Saalekreis). Entdeckt wurde es vor einem Jahrzehnt beim Bau der Autobahn 38 Göttingen-Leipzig. Hätte es aber diesen durch den Aufbau Ost beförderten Zufallsfund nicht gegeben, hätte die Studie vielleicht erst die chronologisch nachfolgenden Individuen mit der indoeuropäischen Ersteinwanderung identifiziert. Deren Bestattungsumstände sind aber einer ganz anderen Kultur zugeordnet, die nach ihrer typischen „Glockenbecher“-Keramik benannt ist und deren Ursprung man eher in West- oder Mitteleuropa, jedenfalls nicht im Osten, vermutet.

Allerdings hat gleichzeitig ein anderes Team den genetischen JamnajaBefund für Individuen aus anderen Schnurkeramik-Gräbern wiederholen können (Allentoft et al. 2015). Dennoch muss sich erst noch erweisen, ob im Lichte weiterer Analysen und archäologischer Skelettfunde die IdentitätsKette Jamnaja-Indoeuropäer-Schnurkeramiker Bestand haben wird. Wir stehen hier vor dem, was man in provokanter Wendung gegen naturwissenschaftliche Vorbehalte hinsichtlich der Geschichtswissenschaft die „Instabilität“ biologischer Erkenntnisse genannt hat (Gordin 2014). In der Tat macht es gerade der rasante technische Fortschritt in der jüngeren aDNA- 
Analyse wahrscheinlich, dass in wenigen Jahren die meisten der heutigen Studien wieder überholt sein könnten. Das lehrt bereits der wissenschaftshistorische Blick auf die Entwicklung bis zur heutigen genetic history (Sommer 2008, Spörri 2013, Bösl 2017).

Auf der einen Seite faszinierende neue technologisch-wissenschaftliche Potentiale und kühne Schlussfolgerungen, auf der anderen Seite fragwürdige Validitäten angesichts geringer Zahlen sowie extreme Schwankungen hinsichtlich der genetischen Stützung kulturwissenschaftlicher Hypothesen: Dieses Bild zeigt sich nicht nur bei der Erforschung des dritten Jahrtausends vor Christus, sondern auch bei Fallstudie 2. Sie betrifft ebenfalls ein Dauerthema der genetic history, die britische Migrationsgeschichte zwischen Antike und Frühmittelalter (dazu Feuchter 2017: 357-359). Angesichts der bisher sehr wechselhaften Ergebnisse überrascht es nicht, dass dieses Problem nun auch auf Grundlage von aDNA angegangen wird, und zwar in gleich zwei Studien. Die eine ist die von Haak und Schiffels präsentierte aus dem Jenaer MPI (Schiffels et al. 2016), die andere wurde von einem Dubliner Team erstellt (Martiniano et al. 2016). Beide betonen die neue Unmittelbarkeit ihres aDNA-Zugriffs auf Geschichte im Gegensatz zu den älteren Arbeiten auf der Basis von moderner DNA. So beansprucht das Jenaer Team etwa, den genetischen impact der angelsächsischen Migrationen anhand der aDNA direkt statt wie bisher indirekt beobachten zu können. Beide Studien analysieren jeweils die aDNA von Individuen, die in einer tausendjährigen Zeitspanne zwischen ca. 100 vor bis ca. 900 nach Christus lebten, also von kurz vor Ankunft der Römer in Britannien bis tief in die Angelsachsenepoche. Auch die Ergebnisse konvergieren: Beide stellen einen großen Unterschied zwischen der aDNA aus der Angelsachsenzeit und jener aus den Perioden davor fest. Letztere erscheinen als eine populationsgenetisch kontinuierliche Vorzeit, ihre Bevölkerung wird somit als ,indigen“ qualifiziert. Die Angelsachsenzeit hingegen stellt einen genetischen Bruch dar, woraus die Autoren auf eine massive Immigration schließen. Beide Studien erreichen auch eine sehr hohe Quantität bei der Sequenzierung. Dem steht allerdings eine sehr geringe Zahl von ,Probanden' gegenüber. Keine der beiden Studien hat mehr als zehn Individuen untersucht. Noch dazu verteilen sich diese auch chronologisch ganz unausgewogen. Die Dubliner Wissenschaftler verfügen nur über eine Probe aus der Angelsachsenzeit, die Jenaer wiederum nur über drei aus der Zeit davor. Schließlich ist die Auswahl auch räumlich jeweils extrem begrenzt. Diese bescheidene Basis wirft die Frage auf, ob auf ihr so weitgehende und zahlenmäßig exakte Schlüsse möglich sind, wie sie zumindest die Jenaer Studie zieht. Zwar trifft es zu, wie Haak und Schiffels bemerken, dass von einem Individuum aus durch genomweite Analyse Daten über eine Vielzahl von Vorfahren gewonnen werden können. Dennoch beseitigt das, wie bereits oben angedeutet, nicht das 
Problem der Zufälligkeit eines Grabfundes und seiner Aussagekraft für die zur Zeit des beprobten Individuums dort lebenden Populationen.

Die Jenaer Studie zeigt auch auf, dass zwei der sieben untersuchten angelsachsenzeitlichen Individuen genetisch ganz bzw. teilweise den indigenen Bevölkerungen der vorangehenden Epoche glichen. Ihre Bestattungskultur ist aber qualitativ nicht von der der anderen, genetisch gegenüber den Indigenen diskontinuierlichen Individuen zu unterscheiden. Das genetisch voll indigene Individuum aus der Angelsachsenzeit lag sogar in dem am reichsten ausgestatteten Grab. Die Autoren schließen daraus, dass es ein kulturelles Angelsachsentum ungeachtet der Abstammung gegeben habe. Ganz ähnliche Verhältnisse zeigt die Dubliner Studie für eine Gruppe römerzeitlicher Britonen auf, unter denen sich ein genetischer ,Ausreißer' findet, der vermutlich aus dem Nahen Osten stammte. Derartige Ergebnisse kommen jedoch für Historiker und Archäologen kaum überraschend. Für sie ist, wie oben erwähnt, die ,Kulturalität' von ethnischer Identität keine bemerkenswerte Neuentdeckung, ebenso wie das Vorkommen hoher individueller Fernmobilität in der Antike.

Mit all dem soll keineswegs gesagt werden, dass die Ergebnisse der heutigen aDNA-Forschung unbeachtlich sind. Im Gegenteil, wir brauchen dringend einen kritischen, offenen Austausch auf Augenhöhe zwischen historischer Genetik und kulturwissenschaftlicher Vergangenheitsforschung (Samida \& Feuchter 2016; Feuchter 2016; Feuchter 2017: bes. 361 f.; Bösl 2017: $350 \mathrm{f}$.). Denn die Herausforderung der genetic history ist da, gleich ob Historiker (und Archäologen) sie annehmen oder nicht. Genetiker haben längst eine eigene Wissensproduktion zur Vergangenheit etabliert, die auch ein starkes Interesse in der Öffentlichkeit findet. Anders als etwa die Radiokarbondatierung oder die Isotopenanalyse geht die genetic history dabei mit dem Anspruch einher, unmittelbare Aussagen von großer Reichweite über menschliche Identitäten zu treffen, die immer auch bis in die Gegenwart reichen (wieviel Prozent Angelsachsen sind unter den Vorfahren der heutigen Briten?). Das liegt daran, dass in einem Zeitalter der epistemischen Genetisierung DNA als ein primärer Identitätsträger gilt. So kritisch derartige Biologisierungen von Identität zu werten sind, so real ist diese gesellschaftliche Geltung der Gene als Identitätsträger auch. Symptomatisch dafür ist, dass das Erbmaterial das Blut als Metapher für eine abstammungsgegebene Identität abgelöst hat. Wo wir früher davon sprachen, etwas „im Blut“ zu haben, sagen wir heute, dass etwas „in unserer DNA steckt“. Kritik an solchen identitären Kurzschlüssen kommt aber erfreulicherweise auch von Genetikern selbst (etwa Jobling 2012). Nicht zuletzt deshalb ist der wechselseitige, kritische Dialog so nötig. 


\section{Literatur}

Allentoft, Morten E. et al. 2015. Population Genomics of Bronze Age Eurasia. Nature (522): $167-172$.

Bösl, Elsbeth 2017. Doing Ancient DNA. Zur Wissenschaftsgeschichte der aDNA-Forschung.

Bielefeld: transcript.

Feuchter, Jörg 2014. Die DNA der Geschichte. Frankfurter Allgemeine Zeitung, 5. November.

Feuchter, Jörg 2016. Über die Herausforderung der Geschichtswissenschaft durch die Genetik. Zwölf Thesen zur "Genetic History“ [Blog-Beitrag vom 23.01.2016]. Mittelalter. Interdisziplinäre Forschung und Rezeptionsgeschichte. URL: http://mittelalter.hypotheses.org/7629 (28.06.2018).

Feuchter, Jörg 2017. Mittelalterliche Migrationen als Gegenstand der "Genetic History“. In: Felix Wiedemann, Kerstin Hofmann und Hans-Joachim Gehrke (Hg.). Vom Wandern der Völker. Migrationserzählungen in den Altertumswissenschaften. Berlin: De Gruyter: 347-370.

Gordin, Michael D. 2014. Comment: Evidence and the Instability of Biology. American Historical Review (119): 1621-1629.

Gibbons, Anne 2015. Revolution in Human Evolution. Science Magazine (349): 362-366.

Haak, Wolfgang et al. 2015. Massive Migration from the Steppe was a Source for Indo-European Languages in Europe. Nature (522): 207-211.

Jobling, Mark A. 2010. Tales the Double Helix Tells. Investigative Genetics $(1,2)$.

Jobling, Mark A. 2012. The Bishop and the Actress. Investigative Genetics $(3,27)$.

Martiniano, Rui et al. 2016. Genomic Signals of Migration and Continuity in Britain before the Anglo-Saxons. Nature Communications (7): 10326.

Pietschmann, Carolina 2014. Zeitreisen mit der molekularen Uhr. MaxPlanckForschung (3): $70-77$.

Renfrew, Colin 2000. Archaeogenetics: Towards a Population Prehistory of Europe. In: Colin Renfrew und Katie Boyle (Hg.). Archaeogenetics: DNA and the Population Prehistory of Europe. Cambridge: McDonald Institute for Archaeological Research: 3-28.

Schiffels, Stephan et al. 2016. Iron Age and Anglo-Saxon Genomes from East England Reveal British. Nature Communications (7): 10408.

Sommer, Marianne 2008. History in the Gene: Negotiations Between Molecular and Organismal Anthropology. Journal of the History of Biology (41): 473-528.

Spörri, Myriam 2013. Reines und gemischtes Blut. Zur Kulturgeschichte der Blutgruppenforschung, 1900-1933. Bielefeld: transcript.

Samida, Stefanie und Jörg Feuchter 2016. Why Archaeologists, Historians and Geneticists Should Work Together - and How. Medieval Worlds (4): 5-21.

Jörg Feuchter

Regesta Imperii - Regesten Kaiser Friedrichs III.

Berlin-Brandenburgische Akademie der Wissenschaften

Jägerstr. 22-23

10117 Berlin

Deutschland

feuchter@bbaw.de 


\title{
Gene, Populationen und Identitäten: Genetic History aus archäologi- scher Sicht
}

\author{
Philipp von Rummel
}

Die Debatte um das Verhältnis der eigenen Quellen zur Geschichtswissenschaft begleitet die Archäologie seit ihren akademischen Anfängen (vgl. etwa Scholkmann 2003). So wirkt die Diskussion um genetic history durchaus vertraut, und es stellt sich die Frage, ob sich Archäologie und Geschichtswissenschaft in den vergangenen Jahren tatsächlich, wie von Wolfgang Haak und Stephan Schiffels am Anfang ihres Beitrages angenommen, stark verändert haben. Ist es wirklich angebracht, wie Kristian Kristiansen (2014) von einer „Revolution“ zu sprechen? Meines Erachtens nicht. Zweifellos hat die Forschung durch die bemerkenswerten Fortschritte bei der Entwicklung moderner DNA-Sequenzierungstechnologien riesige Sprünge gemacht und erschließt ungeahnte neue Datenmengen. Ähnliches ist auch in anderen Bereichen zu beobachten, etwa der Prospektion, der dreidimensionalen Dokumentation oder der Materialanalyse. Es besteht auch kein Zweifel daran, dass die Digitalisierung durch Vernetzung, Statistik und Modellierung die Bewältigung dieser Daten ermöglicht und neue Fragen eröffnet. Die Fächer haben sich jedoch weder stark verändert noch ist eine Revolution festzustellen. Angesichts neuer Quellen und neuer Verfahren zeigt sich vielmehr eine erneute Debatte über die Justierung unterschiedlicher Quellenspezialisierungen innerhalb der Geschichtswissenschaft (Samida \& Feuchter 2016).

\section{Genome als historische Quellen}

In akademisch institutionalisierten Fächern werden notwendige universitär-administrative Abgrenzungen zuweilen auch zu wissenschaftlich-heuristischen Grenzen. Hierin liegt gerade auch in der Debatte um genetic history eine Gefahr, trotz alter und wiederholter Appelle an eine „Ent-Disziplinierung“ der Geschichtswissenschaft (etwa Oexle 1996: 10). Die Debatte wird jedenfalls einfacher, wenn die Gesamtheit dessen, was Auskunft über die Vergangenheit gibt, als historische Quelle begriffen wird. Ganz gleich, ob dies ein Knochen ist, eine Gensequenz, eine Keramikscherbe, eine Fibel, 
ein Gebäude, eine Abfallgrube, eine Münze oder ein Text: Sie alle sind im weiteren Sinne Produkte historischer Handlungen, und sie alle helfen, Vergangenheit verständlich zu machen. Historiker sind in diesem Sinne alle, die historische Fragen stellen. Ihre Quellen sind dabei a priori hierarchielos. Unabhängig von möglicher Intention bei ihrer Entstehung gewinnen Quellen ihre Wertigkeit erst durch die jeweilige Frage, die an sie herangetragen wird. Da unterschiedliche Quellen ein jeweils eigenes Potential zur Beantwortung spezifischer Fragen haben, ist es die Fragestellung, die Hierarchien schafft.

Es wäre ein Fehler, diese kontextgebunden entstehenden Hierarchien für absolut zu halten. DNA aus Knochen und Zähnen bestatteter Individuen kann etwa für die Verwandtschaftsanalyse eines Gräberfeldes wesentliche konkretere Einblicke liefern als die Analyse der Lage, Grabform oder Ausstattung der Gräber. Für die Geschichte des griechischen Tempelbaus oder die Interpretation römischer Skulptur ist sie dagegen eher irrelevant. Auch die Frage von ,Objektivität' schafft keine naturgegebene Quellenhierarchie. Vor einer Fragestellung, vor Quellenkritik und Interpretation ist ein Knochen genauso ,objektiv' wie ein Steinwerkzeug, ein Bronzeschwert oder Schrift auf einem Schriftträger. Diese Nivellierung beschneidet kein Fachgebiet in seiner Kompetenz, seiner Zuständigkeit oder in der Bedeutung der notwendigen Spezialisierung. Sie verpflichtet aber alle am Diskurs Beteiligten zur Auseinandersetzung mit historisch-archäologischer Quellenkritik und dazu, Rechenschaft über die Grenzen der Quellen, der Methoden und der Interpretation abzulegen. Entscheidend ist die vollumfängliche Integration des Interpretationsdiskures zur jeweiligen Forschungsfrage ohne Ausweichmöglichkeit mittels eines entschuldigenden Verweises auf eine jeweils andere Disziplin.

\section{Biologische Population und soziale Gruppe}

Haak und Schiffels ist zuzustimmen, wenn sie Missverständnisse, unterschiedliche Forschungstraditionen und unterschiedliche wissenschaftliche Terminologie als Kernproblem benennen. Neben dem von ihnen zu Recht als problematisch bezeichneten Begriff der Migration oder unterschiedlichen Raum- und Mobilitätskonzepten (Hofmann 2016: 100-102) ist auch der Begriff der Population ein besonders großer Stolperstein des gemeinsamen Gesprächs. Das Problem dieses grundlegenden Begriffes ist seine hohe Unschärfe, die schon in der Biologie selbst beginnt und wesentlich größer wird, wenn soziologische und historische Ebenen hinzukommen. Das, was die Genetiker als Populationen ansprechen, erlaubt es, durch das Herausarbeiten von genetischen Kontinuitäten und Diskontinuitäten auf (biolo- 
gische) Vermischungsereignisse zu schließen (Haak \& Schiffels). Der zentrale Begriff der Population ist in der empirischen Populationsgenetik aber erstaunlicherweise nicht fest definiert (vgl. Stoneking 2017), sondern wird pragmatisch, von Fall zu Fall unterschiedlich, selten biologisch und häufig mit Rekurs auf gesellschaftlich erzeugte Kategorien konzipiert. Wenn die biologischen Kategorien aber nicht klar von anderen Begrifflichkeiten menschlicher Gruppenbildung, von Verbreitungsbildern archäologischer Sachkultur oder Sprachgruppen unterschieden werden, liegen Missverständnisse nicht fern. Grundlage moderner genetischer Studien sind häufig Populationsdefinitionen, deren Grenzen sich an modernen Staaten orientieren (wenn nicht an noch schwerer zu fassenden Definitionen ,rassischer', sprachlicher oder sozialer Klassifikation). Auf diese Weise gerät die anthropologische Population semantisch nicht selten in die Nähe des schwierigen Begriffes des „Volkes“. Dies trifft wiederum zusammen mit einem noch in weiten Teilen der Gesellschaft lebendigen essentialistischen Volksbegriff, der nicht nur von einer Bluts- und Geistesgemeinschaft eines Volkes ausgeht, sondern auch von einem bestimmten „Volkstum“, das sich etwa in Sprache, Kunst und Kultur äußere. Es ist aber von grundlegender Bedeutung, diese unterschiedlichen Ebenen der Analyse nicht apriorisch als Einheit zu begreifen, sondern im wissenschaftlichen Verfahren zu differenzieren. Haak und Schiffels sind sich dieses Problems bewusst. In Fallbeispiel 2 erweitern historische Ethnonyme wie etwa das der „Angelsachsen“ den Argumentationsgang und werfen die Frage der Verbindung dieser Termini mit biologischen Gruppen auf. Die Genetik steht hier vor dem gleichen Problem wie die Archäologie, die versucht, bestimme Formen und Komplexe materieller Kultur mit historisch bekannten Gruppen zu verbinden: Wenn ein Verstorbener auf Grund der Anlage seines Grabes, der Grabausstattung oder auch seines Erbgutes etwa als Angelsachse beschrieben werden soll, muss man wissen, was ein Angelsachse eigentlich ist. Schon diese einfach scheinende Frage ist aber nicht nur schwer zu beantworten, sondern sogar bei einem auch in schriftlichen Quellen besser belegtem Fall wie den Goten in Italien heftig umstritten. Das, was etwa ein Gote ist, was gotische Identität oder Ethnizität ist, oder was einen Goten von einem Römer unterscheidet, ist kein stabiles Fundament, auf dem Archäologie oder Genetik kritiklos ihre Interpretationsgebäude errichten könnten (von Rummel 2010). Daher muss der Aussage von Haak und Schiffels widersprochen werden, Simplifizierungen von Begriffen wie „Schnurkeramiker“, „Kelten“ oder „Langobarden“ dienten bei der Kontextualisierung der genetischen Ergebnisse als in Kauf zu nehmendes Mittel zum Zweck. In einem Bereich, in dem Genauigkeit und maximale Differenzierung essentiell sind, um komplexe gesellschaftliche und kulturelle Strukturen zu beschreiben, sind bewusste, genau dies übergehende Simplifizierungen nicht von Nutzen. 


\section{Archäologie der Identität}

$\mathrm{Zu}$ Recht weisen Haak und Schiffels darauf hin, dass ein Stein des Anstoßes in der Debatte um die Interpretation genetischer Befunde die Frage der Verbindung unterschiedlicher Quellengattungen darstellt. Es ist in der Tat die Frage der ethnischen Interpretation archäologischer Funde und Befunde, die angesichts des archäologischen Kontexts beprobter DNA weite Teile der Diskussion bestimmt und zuweilen, wie Haak und Schiffels schreiben, an eine „Heraufbeschwörung der alten, tot geglaubten Geister in frischem Gewand" erinnert. Aus archäologischer Perspektive muss hier ein wichtiger Punkt unterstrichen werden: Haak und Schiffels gehen, wie etwa auch Kristiansen und viele andere, davon aus, dass der Missbrauch von Gustaf Kossinnas 1911 formulierter „siedlungsarchäologischer Methode“ dazu geführt habe, dass in den Nachkriegsjahren ,jede mögliche Verbindung von Archäologie, Sprache und Sprach- bzw. Sachkulturträger, das heißt einer Bevölkerungsgruppe ausgeschlossen wurde“. Diese Annahme ist jedoch nicht richtig. Nach dem zweiten Weltkrieg wurde zwar die Terminologie bereinigt und eindeutig ideologisch bedingte Interpretationen und unwissenschaftliche Projektionen aus der Wissenschaft verbannt, ansonsten blieb die deutschsprachige Archäologie jedoch von Kontinuität bestimmt. ,Kultur' diente und dient weiterhin nicht nur in der Archäologie, sondern auch der allgemeinen gesellschaftlichen Debatte häufig unhinterfragt als Kern kollektiver Sinngebungen und Identitätsstiftung.

Durch eine verzerrende Darstellung der post-prozessualen Archäologie als mächtigem, angebliche Denkverbote erlassenden Gegner (vgl. etwa Kristiansen 2014: 14) schafft diese Argumentation ein Feindbild, an dem sich das Neue des eigenen Zugangs hervorragend kontrastieren lässt. Dieser Feind hat jedoch nie existiert. Zumindest müsste zwischen ganz verschiedenen Forschungstraditionen unterschieden werden. Eine Verbindung archäologischer Sachkulturgruppen mit handelnden sozialen Gruppen war sowohl in der ur- als auch in der frühgeschichtlichen Archäologie in weiten Teilen Europas in den letzten Jahrzehnten gang und gäbe und ist es vielfach noch immer. Man hielt sich weithin an Hans Jürgen Eggers (1959: 200), der schrieb, „die Vorgeschichte würde sich als historische Wissenschaft selber aufgeben, würde sie nicht immer und immer wieder den Versuch machen, auch das Problem der ethnischen Deutung zu lösen“. Eine generelle kritische Auseinandersetzung mit der Praxis ethnischer Interpretation begann in den 1990er Jahren (Brather 2004; Fehr 2010; Pohl \& Mehofer 2010) und ist bis heute Gegenstand einer ernsthaften Debatte, vor allem im Bereich der frühgeschichtlichen Archäologie. Zudem wurde und wird das Thema der Mobilität von Gruppen in der Archäologie nicht generell vermieden, wie Haak und Schiffels schreiben, sondern ist trotz ablehnender Stimmen 
und mangelnder methodologischer Fundierung des Konzepts stets höchst präsent gewesen (Burmeister 2016). Migrationen wie Borgolte und Tischler (2012: 11) als „Königsweg der kulturalistischen Globalgeschichte“ zu beschreiben, führt aber andererseits auch zu weit, da überhaupt kein Anlass besteht, die vielen anderen Mechanismen kultureller Vernetzung und Veränderung in den Hintergrund zu schieben.

Die Erforschung vergangener Selbst- und Fremdbilder, von Rollen, Abgrenzungen und Zuschreibungen, von Identitäten und Alteritäten ist ein äußerst komplexes Feld (Pohl 2013; Brather 2016). So falsch es wäre, die vermutete Existenz essentialistischer Entitäten zur Interpretationsgrundlage zu erheben, so falsch wäre es auch, einem einzigen bestimmten Faktor, etwa dem Erbgut, die Deutungshoheit oder gar einen Wahrheitsanspruch (hard facts) zuzusprechen. Das menschliche Selbstverständnis und die Gemeinschaften, in denen es sich bildet, sind komplexe soziale Konstruktionen und Gegenstand ständiger Aushandlungsprozesse unter Einbeziehung vieler Faktoren, sich stetig wandelnd in Raum und Zeit. Ein Begriff wie „Langobarden“ bezeichnet im Gegensatz zu „Jäger-Sammler“ nicht die „Vergegenständlichung von materieller Kultur, Sprache, oder gar eine Wirtschaftsweise" (Haak \& Schiffels), sondern eine konkrete historische Gemeinschaft, die Schnittmengen mit Faktoren wie Sprache, materielle Kultur oder Wirtschaftsweise aufweisen kann, aber keineswegs mit ihnen identisch ist. Genetische Quellen steuern hier interessante und wichtige Informationen bei. Dabei machen sie einen ohnehin schon vielschichtigen Interpretationsvorgang allerdings nicht einfacher oder objektiver, sondern im Gegenteil noch komplexer.

Die feine Differenzierung der unterschiedlichen Faktoren sozialer Identität ist die große Errungenschaft der historisch-archäologischen Forschung der letzten Jahrzehnte. Für eine erfolgreiche Zusammenarbeit ist es notwendig, dass sich alle Beteiligten auf dieses Differenzierungsniveau begeben. Gleichzeitig dürfen bei aller Begeisterung über die neuen Möglichkeiten molekulargenetischer Untersuchungen die Quellen, die Auskunft über die vielen anderen, nicht-biologischen Aspekte der Menschheitsgeschichte geben, keine Vernachlässigung erfahren.

\section{Literatur}

Borgolte, Michael und Matthias M. Tischler 2012. Einleitung. In: Dies. (Hg.). Transkulturelle Verflechtung im mittelalterlicher Jahrtausend. Europa - Ostasien - Afrika. Darmstadt: Wissenschaftliche Buchgesellschaft: 9-20.

Brather, Sebastian 2004. Ethnische Interpretationen in der frühgeschichtlichen Archäologie. Geschichte, Grundlagen und Alternativen. Berlin und New York: De Gruyter. 
Brather, Sebastian 2016. New Questions Instead of Old Answers: Archaeological Expectations of a DNA Analysis. medieval worlds (4): 22-41.

Burmeister, Stefan 2016. Archaeological Research on Migration as a Multidisciplinary Challenge. medieval worlds (4): 42-64.

Fehr, Hubert 2010. Germanen und Romanen im Merowingerreich. Frühgeschichtliche Archäologie zwischen Wissenschaft und Zeitgeschehen. Berlin und New York: De Gruyter.

Feuchter, Jörg 2017. Mittelalterliche Migrationen als Gegenstand der ,Genetic History‘. In: Felix Wiedemann, Kerstin P. Hofmann und Hans-Joachim Gehrke (Hg.). Vom Wandern der Völker. Migrationserzählungen in den Altertumswissenschaften, Berlin: Edition Topoi: 347-370.

Hofmann, Kerstin 2016. With Víkingr into the Identity Trap: When Historiographical Actors Get a Life of their Own. medieval worlds (4): 91-122.

Kristiansen, Kristian 2014. Towards a New Paradigm? The Third Science Revolution and its Possible Consequences in Archaeology. Current Swedish Archaeology (22): 11-34.

Oexle, Otto Gerhard 1996. Geschichtswissenschaft im Zeichen des Historismus. Studien zu Problemgeschichten der Moderne. Göttingen: Vandenhoeck\&Ruprecht.

Pohl, Walter 2013. Introduction - Strategies of Identification: A Methodological Profile. In: Walter Pohl und Gerda Heydemann (Hg.). Strategies of Identitfication. Ethnicity and Religion in Early Medieval Europe. Turnhout: Brepols: 1-64.

Pohl, Walter und Mathias Mehofer (Hg.) 2010. Archaeology of Identity - Archäologie der Identität. Wien: Verlag der Österreichischen Akademie der Wissenschaften.

Rummel, Philipp von 2010. Gotisch, barbarisch oder römisch? Methodologische Überlegungen zur ethnischen Interpretation von Kleidung. In: Walter Pohl und Mathias Mehofer (Hg.). Archaeology of Identity - Archäologie der Identität. Wien: Verlag der Österreichischen Akademie der Wissenschaften: 51-77.

Samida, Stefanie und Jörg Feuchter 2016. Why Archaeologists, Historians and Geneticists Should Work Together - and How. medieval worlds (4): 5-21.

Scholkmann, Barbara 2003. Die Tyrranei der Schriftquellen? Überlegungen zum Verhältnis materieller und schriftlicher Überlieferung in der Mittelalterarchäologie. In: Marlies Heinz, Manfred K.H. Eggert und Ulrich Veit (Hg.). Zwischen Erklären und Verstehen? Beiträge zu den erkenntnistheoretischen Grundlagen archäologischer Interpretation. Münster: Waxmann: 239-257.

Stoneking, Marc 2017. An Introduction to Molecular Anthropology. Hoboken, NJ: Wiley.

\section{Philipp von Rummel}

Deutsches Archäologisches Institut, Zentrale

Podbielskiallee 69-71

14195 Berlin

Deutschland

generalsekretaer@dainst.de 